\title{
Estimation of Turbulent Heat Fluxes via Assimilation of Air Temperature and Specific Humidity into an Atmospheric Boundary Layer Model
}

\author{
E. TAJFAR AND S. M. BATENI \\ Department of Civil and Environmental Engineering, and Water Resources Research Center, \\ University of Hawai'i at Mānoa, Honolulu, Hawaii \\ S. A. MARgulis \\ Department of Civil and Environmental Engineering, University of California, Los Angeles, \\ Los Angeles, California \\ P. GENTINE \\ Earth and Environmental Engineering, and Earth Institute, Columbia University, \\ New York, New York \\ T. Auligne \\ Joint Center for Satellite Data Assimilation, Camp Springs, Maryland, and \\ University Corporation for Atmospheric Research, Boulder, Colorado
}

(Manuscript received 9 May 2019, in final form 7 November 2019)

\begin{abstract}
A number of studies have used time series of air temperature and specific humidity observations to estimate turbulent heat fluxes. These studies require the specification of surface roughness lengths for heat and momentum (that are directly related to the neutral bulk heat transfer coefficient $C_{\mathrm{HN}}$ ) and/or ground heat flux, which are often unavailable. In this study, sequences of air temperature and specific humidity are assimilated into an atmospheric boundary layer model within a variational data assimilation (VDA) framework to estimate $C_{\mathrm{HN}}$, evaporative fraction (EF), turbulent heat fluxes, and atmospheric boundary layer (ABL) height, potential temperature, and humidity. The developed VDA approach needs neither the surface roughness parameterization (as it is optimized by the VDA approach) nor ground heat flux measurements. The VDA approach is tested over the First International Satellite Land Surface Climatology Project Field Experiment (FIFE) site in the summers of 1987 and 1988. The results indicate that the estimated sensible and latent heat fluxes agree fairly well with the corresponding measurements. For FIFE 1987 (1988), the daily sensible and latent heat fluxes estimates have a root-mean-square error of $25.72 \mathrm{~W} \mathrm{~m}^{-2}\left(27.77 \mathrm{~W} \mathrm{~m}^{-2}\right)$ and $53.63 \mathrm{~W} \mathrm{~m}^{-2}$ $\left(48.22 \mathrm{~W} \mathrm{~m}^{-2}\right)$, respectively. In addition, the ABL height, specific humidity, and potential temperature estimates from the VDA system are in good agreement with those inferred from the radiosondes both in terms of magnitude and diurnal trend.
\end{abstract}

\section{Introduction}

The sensible $(H)$ and latent (LE) heat fluxes are important components of Earth's energy budget and its climate system, which directly influence the properties of the boundary layer. The accurate estimation of turbulent heat fluxes between the land surface and atmospheric boundary layer $(\mathrm{ABL})$ is required in many fields

Corresponding author: Sayed M. Bateni, smbateni@hawaii.edu such as drought monitoring, cultivation and irrigation management systems, modeling of global climate regimes, weather forecasting, and water resources management (Liou and Kar 2014; Santanello et al. 2018).

Using ground-based instruments to measure turbulent heat fluxes is costly and challenging. Consequently, a number of approaches have been developed to estimate turbulent heat fluxes using a variety of measurements that are indirectly related to fluxes (Kalma et al. 2008; Li et al. 2010; Maes and Steppe 2012; Bateni and Entekhabi 2012b, 2013b; 
Xu et al. 2014, 2015; Zhuang and Wu 2015; Lu et al. 2016; Brenner et al. 2017; Abdolghafoorian et al. 2017). One of the methods of estimating turbulent heat fluxes is through assimilation of sequences of land surface temperature (LST) observations into the force-restore or heat diffusion equation within a variational data assimilation (VDA) framework (Caparrini et al. 2003; Crow and Kustas 2005; Bateni and Entekhabi 2012a,b; Bateni et al. 2013a,b, 2014; Xu et al. 2015, 2016, 2018; Abdolghafoorian and Farhadi 2016; Abdolghafoorian et al. 2017). These studies used the implicit information in the sequences of LST observations to partition the available energy into sensible and latent heat fluxes. Performance of these approaches typically degrades in wet and/or heavily vegetated sites where evapotranspiration is often in stage I (i.e., energy controlled) and controlled mainly by atmospheric factors rather than by land surface processes. More importantly, they need to specify the soil thermal conductivity and heat capacity as well as deep soil temperature, which are often unavailable. Several studies (e.g., Sini et al. 2008; Abdolghafoorian and Farhadi 2019) improved performance of VDA approaches by assimilating soil moisture or antecedent precipitation index (API).

In a departure with assimilating LST measurements, a number of studies showed that the screen-level air temperature and humidity measurements in addition to surface parameterization in itself contain useful information about soil moisture (Mahfouf 1991; Bouttier et al. 1993a,b; Mahfouf et al. 2000, 2009; Douville et al. 2000; Hess 2001; Drusch and Viterbo 2007; de Rosnay et al. 2013; Ren and Xue 2016; de Lannoy et al. 2016) and turbulent heat fluxes (Holtslag and Van Ulden 1983; Margulis and Entekhabi 2001, 2003; Alapaty et al. 2001; Balsamo et al. 2007; Shang et al. 2007; Salvucci and Gentine 2013; Rigden and Salvucci 2015; Gentine et al. 2016; Lum et al. 2017). These studies typically require specification of surface roughness for heat and momentum (that are directly related to the neutral bulk heat transfer coefficient $C_{\mathrm{HN}}$ ) as well as ground heat flux to estimate the sensible and latent heat fluxes, which are mostly unavailable.

Owing to the abovementioned drawbacks of the existing VDA approaches (e.g., poor performance in wet/heavily vegetated sites, and the need for the specification of deep soil temperature and soil thermal properties) and the fact that the sequences of screenlevel air temperature and humidity contain information on the turbulent heat fluxes, this study aims at estimating turbulent heat fluxes by assimilating the screen-level air temperature and specific humidity into an ABL model. The main unknown parameters of the VDA approach are $C_{\mathrm{HN}}$ (that scales the sum of turbulent heat fluxes) and evaporative fraction (EF; that represents the partitioning between turbulent heat fluxes). The proposed VDA finds the optimal values of $C_{\mathrm{HN}}$ and EF by the synergistic assimilation of air temperature and specific humidity into an ABL model. It is worth mentioning that this study assimilates only the state variables of atmosphere (i.e., air temperature and specific humidity), and not the state variable of land surface (i.e., LST). The advantages of the developed VDA approach are 1) it can generate turbulent heat fluxes even when air temperature and humidity observations are not available or there are data gaps, 2) it does not need the surface roughness for heat and momentum (or $C_{\mathrm{HN}}$ ) because the VDA finds the optimal value of $\left.C_{\mathrm{HN}}, 3\right)$ it does not need the ground heat flux measurements, 4) it does not require any ancillary input data such as soil type and moisture, 5) it works by routine weather station data (i.e., air temperature and humidity, wind speed, incoming solar radiation), LST, and vegetation height that can be obtained by in situ measurements and/or remote sensing data (https://www.landfire.gov/ vegetation.php), and 6) it maintains physical consistency so that noisy or erroneous observations (such as those polluted by advection and synoptic variability) are given little weight to estimate surface heat fluxes.

A brief description of the surface energy balance (SEB) equation and ABL model is provided in section 2. Section 3 explains the developed VDA framework. Section 4 describes the First International Satellite Land Surface Climatology Project (ISLSCP) Field Experiment (FIFE) dataset. Section 5 presents the results. Finally, conclusions are given in section 6 . A complete list of the symbols used in this study is given in appendix A.

\section{Methodology}

\section{a. Surface energy balance}

The SEB equation is given by

$$
R_{n}=H+\mathrm{LE}+G
$$

where $R_{n}$ is the net surface radiation, $H$ is the sensible heat flux, LE is the latent heat flux, and $G$ is the ground heat flux. The net surface radiation $R_{n}$ is defined as

$$
R_{n}=(1-\alpha) R_{s}^{\downarrow}+R_{l}^{\downarrow}-\varepsilon_{s} \sigma T^{4},
$$

where $\alpha$ is the surface albedo, $R_{s}^{\downarrow}$ is the incoming solar radiation, $\varepsilon_{s}$ is the surface emissivity, $\sigma$ is the Stefan-Boltzman constant, and $T$ is the land surface temperature. Here, $R_{l}^{\downarrow}=\epsilon_{a} \sigma T_{a}^{4}$ is the incoming longwave radiation (where $T_{a}$ is the air temperature at the 


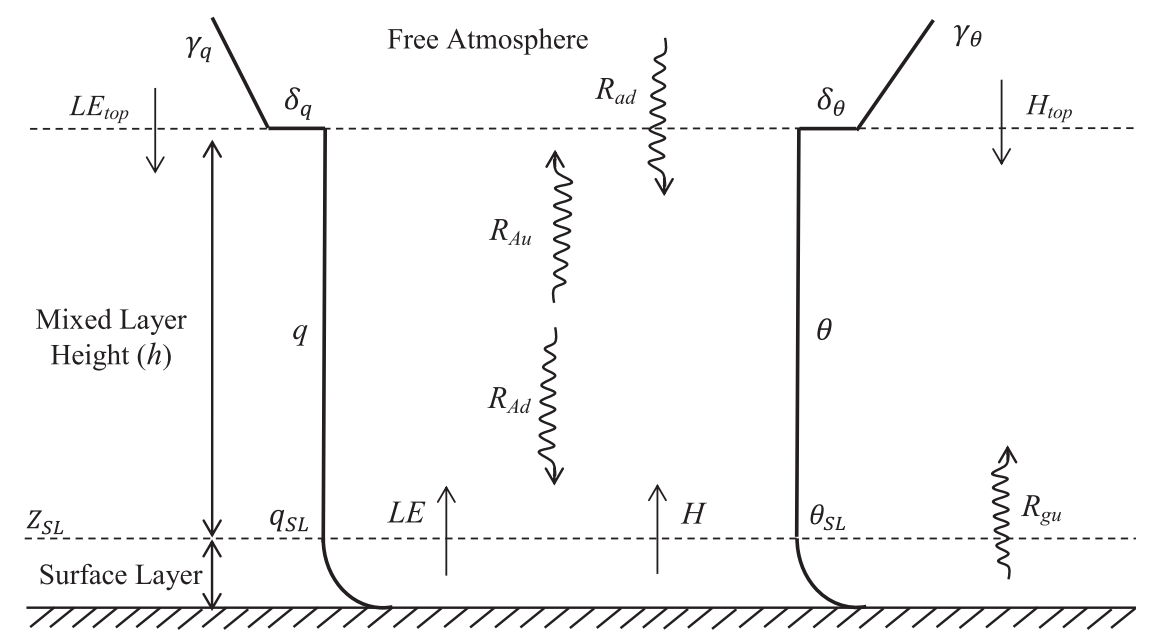

FIG. 1. Idealized profiles of ABL states $(\theta$ and $q)$ and corresponding fluxes between the surface layer, mixed layer, and overlying atmosphere.

screen level $z_{\text {screen }}$ ), and $\epsilon_{a}$ is the atmospheric emissivity, which is obtained from the Idso (1981) formulation.

The sensible heat flux is computed using the Richardson number:

$$
H=\rho c_{p} C_{\mathrm{HN}} f(\mathrm{Ri}) u_{a}\left(T-T_{a}\right),
$$

where $c_{p}$ is the specific heat capacity of air, $\rho$ is the air density, and $u_{a}$ is the wind speed at the screen level. The term $C_{\mathrm{HN}}$ is the neutral bulk heat transfer coefficient, which depends on the characteristics of the landscape (surface roughness and canopy density). The effect of atmospheric stability on sensible heat flux is taken into account by the atmospheric stability correction function $f$, which is a function of the Richardson number ( $\mathrm{Ri}$ ). The stability correction function proposed by Caparrini et al. (2003) is used in this study.

The estimation objectives of this study are the sum of turbulent heat fluxes $(H+\mathrm{LE})$, and their partitioning [i.e., the evaporative fraction, $\mathrm{EF}=\mathrm{LE} /(\mathrm{LE}+H)]$. The term $C_{\mathrm{HN}}$ scales the sum of turbulent heat fluxes (i.e., $H+\mathrm{LE}$ ), and EF scales their partitioning (Bateni et al. 2013a,b; Xu et al. 2014; Lu et al. 2016). The term $C_{\mathrm{HN}}$ represents the effect of land surface characteristics on air turbulent conductivity and is the first unknown of the VDA system. It is dependent mainly on the geometry of the landscape and vegetation, and changes with variations in canopy phenology (Caparrini et al. $2004 \mathrm{a}, \mathrm{b})$. In this study, it is assumed that $C_{\mathrm{HN}}$ varies on a monthly time scale.

Gentine et al. (2007, 2011) showed that EF is almost constant for daytime hours on days without precipitation. In this study, EF (the second unknown of the VDA system) is assumed to be constant during the daytime assimilation window [0900-1600 local time (LT)] for each day so that latent heat flux can then be evaluated as

$$
\mathrm{LE}=\frac{\mathrm{EF}}{1-\mathrm{EF}} H
$$

\section{b. ABL model}

The state of the ABL over a land surface is strongly connected to the magnitude of the surface heat fluxes. Margulis and Entekhabi (2001) used a mixed-layer model to simulate the ABL (Fig. 1). The entrainment fluxes link the ABL system to the overlying free atmosphere. These fluxes heat up and dry the mixed layer, influence the temperature and humidity of the mixed layer, ultimately affecting the surface energy and moisture budgets. Different components of the ABL model are explained in sections $2 b(1)-2 b(4)$.

\section{1) ABL ENERGY AND MOISTURE BUDGET}

In this study, we used a mixed-layer model, which performs very well against the more complex large eddy simulations (Garcia and Mellado 2014; Gentine et al. 2015; Tajfar et al. 2019). The profiles of potential temperature $\theta$ and specific humidity $q$ are assumed to be uniform in the mixed layer. The air layer between the land surface and the mixed layer is called the surface layer, which is convectively unstable during the daytime. The top of the surface layer is specified as $10 \%$ of the mixed-layer top (Margulis and Entekhabi 2001; Gentine et al. 2016; Tajfar 2019). As shown in Fig. 1, the entrainment zone connects the mixed layer to the free atmosphere and is illustrated by instantaneous jumps in the $\theta$ and $q$ profiles (Margulis and Entekhabi 2001; Garcia and Mellado 2014; 
Gentine et al. 2015; Tajfar et al. 2019, manuscript submitted to J. Hydrol.).

The conservation of potential temperature and specific humidity in the mixed layer follow the energy budget:

$$
\begin{aligned}
& \rho c_{p} h \frac{d \theta}{d t}=\left(R_{\mathrm{ad}}+R_{\mathrm{gu}}\right) \varepsilon_{m}-R_{\mathrm{Ad}}-R_{\mathrm{Au}}+H+H_{\mathrm{top}} \\
& \rho h L_{v} \frac{d q}{d t}=\mathrm{LE}+\mathrm{LE}_{\mathrm{top}}
\end{aligned}
$$

where $h$ is the mixed-layer height; $t$ is the time; $R_{\text {ad }}$ and $R_{\mathrm{gu}}$ are the longwave radiation from the free atmosphere overlying the ABL and the land surface beneath, respectively; $R_{\mathrm{Ad}}$ and $R_{\mathrm{Au}}$ are the downward and upward longwave radiative fluxes originating from within the mixed layer, respectively; $H_{\text {top }}$ and $\mathrm{LE}_{\text {top }}$ are the entrainment sensible and latent heat flux, respectively; $\varepsilon_{m}$ is the mixed-layer bulk emissivity; and $L_{v}$ is the latent heat of vaporization. The terms $\theta$ and $q$ constitute the state variables of the ABL model, which are obtained by Eqs. (5a) and (5b), respectively.

Initial conditions for $\theta$ and $q$ [i.e., $\theta\left(t=t_{o}\right)$ and $q\left(t=t_{o}\right)$, where $\left.t_{o}=0900 \mathrm{LT}\right]$ are required to solve the ABL state [Eqs. (5a) and (5b)]. The potential temperature at the level of $1000 \mathrm{hPa}$ (i.e., $\theta_{a}$ ) is found from the screenlevel air temperature $T_{a}$ via $\theta_{a}=T_{a}\left(P_{0} / P_{s}\right)^{R_{d} / c_{p}}$ (where $R_{d}$ is the gas constant of dry air, $P_{s}$ is the surface pressure, and $P_{0}$ is $1000 \mathrm{hPa}$ ) (Shuttleworth 2012). Appendix B explains how $\theta\left(t=t_{o}\right)$ and $q\left(t=t_{o}\right)$ are obtained from $\theta_{a}\left(t=t_{o}\right)$ and $q_{a}\left(t=t_{o}\right)\left(q_{a}\right.$ is the specific humidity at the screen level of $2 \mathrm{~m}$ ) via Monin-Obukhov Similarity Theory (MOST) (Rigden and Salvucci 2015; Gentine et al. 2016; Tajfar 2019). MOST describes profiles of air temperature and humidity within the surface layer (Jimenez et al. 2012). Hence, it is used in this study (appendix B) to relate the initial conditions for Eqs. (5a) and (5b) [i.e., $\theta\left(t=t_{o}\right)$ and $q\left(t=t_{o}\right)$ ] to their corresponding screen-level values [i.e., $\theta_{a}\left(t=t_{o}\right)$ and $\left.q_{a}\left(t=t_{o}\right)\right]$.

Advection may undermine the assumption of constant potential temperature and specific humidity in the mixed layer, resulting in errors in the turbulent heat fluxes estimates. In this study, it is assumed that the advection is insignificant. Solar absorption is also neglected in the ABL model.

\section{2) MiXED-LAYER HEIGHT}

The height of the mixed layer $h$ evolves dynamically during the day. During the day, the ABL grows mainly because of the virtual heat flux $H_{v}$ at the land surface
(Kim and Entekhabi 1997, 1998a,b). The diurnal range of the ABL height generally changes from $\sim 100-500 \mathrm{~m}$ in the early morning to $\sim 1-3 \mathrm{~km}$ by late afternoon (Margulis and Entekhabi 2001). The daytime growth of the ABL height is given by (Smeda 1979; Kim and Entekhabi 1997, 1998a,b; Bagley et al. 2011)

$$
\frac{d h}{d t}=\frac{2\left(G_{*}-D_{1}-D_{2}\right) \theta}{g h \delta_{\theta}}+\frac{H_{v}}{\rho c_{p} \delta_{\theta}},
$$

where the different terms are defined by

$$
\begin{aligned}
G_{*} & =u_{\mathrm{SL}} u_{*}^{2}, \\
D_{1} & =u_{\mathrm{SL}} u_{*}^{2}\left(1-e^{-\varphi h}\right), \\
D_{2} & =0.4\left(\frac{g h}{\theta} \frac{H_{v}}{\rho c_{p}}\right), \quad \text { and } \\
H_{v} & =H+0.61 \theta c_{p} E \approx H+0.07 \mathrm{LE} .
\end{aligned}
$$

The first and second terms on the right-hand side of Eq. (6a) represent the ABL growth due to mechanically generated turbulent energy and the surface virtual heat flux, respectively. The term $G_{*}$ is the production of mechanical turbulent energy, $g$ is gravitational acceleration, $u_{\mathrm{SL}}$ is the wind speed at the top of the surface layer, which is obtained from the wind speed at the screen level using MOST (see appendix B), $u_{*}$ is the friction velocity, $H_{v}$ is the virtual heat flux at the surface, $E$ is the evaporative rate from ground, and $\varphi$ is the mechanical turbulence dissipation parameter, which is set to 0.01 (Kim and Entekhabi 1998b; Margulis and Entekhabi 2001; Bagley et al. 2011).

As indicated in Fig. 1, the ABL model contains discrete jumps in temperature and humidity at the top of the boundary layer. The intensities of these jumps $\left(\delta_{\theta}\right.$ and $\left.\delta_{q}\right)$ change along with the other components of the ABL system as air from the overlying free-atmosphere entrains into the mixed layer and surface fluxes change the state of ABL (Bagley et al. 2011). The $\delta_{\theta}$ increases as the boundary layer grows and decreases when the boundary layer warms. The expression for $\delta_{\theta}$ can be written as (Margulis and Entekhabi 2001)

$$
\frac{d \delta_{\theta}}{d t}=\gamma_{\theta} \frac{d h}{d t}-\frac{d \theta}{d t} .
$$

Similarly, $\delta_{q}$ increases as the boundary layer grows and decreases when the boundary layer becomes moister. The equation for $\delta_{q}$ is (Margulis and Entekhabi 2001; Bagley et al. 2011) 


$$
\frac{d \delta_{q}}{d t}=\gamma_{q} \frac{d h}{d t}-\frac{d q}{d t}
$$

$\gamma_{\theta}$ and $\gamma_{q}$ are the lapse rates in potential temperature and specific humidity above the mixed layer.

\section{3) ENTRAINMENT FLUXES}

The mixed layer is usually topped by inversions in specific humidity and potential temperature (Fig. 1). As the boundary layer grows, dry air from above enters into the mixed layer, resulting in the sensible and latent heat fluxes between the free atmosphere and mixed layer. The entrainment sensible heat flux from above the mixed layer $\left(H_{\text {top }}\right)$ contributes to the mixed-layer growth (Stull 1994). The entrainment latent heat flux $\left(\mathrm{LE}_{\text {top }}\right)$ dries up the mixed layer because the free tropospheric air is typically drier than the mixed layer (Stull 1994). The equations for $H_{\text {top }}$ and $\mathrm{LE}_{\text {top }}$ can be derived by considering the conservation of heat and moisture across the interface between the free atmosphere and mixed layer:

$$
\begin{aligned}
H_{\text {top }} & =A H, \\
\mathrm{LE}_{\text {top }} & =\rho L_{v} \delta_{q} \frac{d h}{d t} .
\end{aligned}
$$

A typical value of 0.2 is used for $A$ (Gentine et al. 2015; Garcia and Mellado 2014; Tajfar et al. 2019, manuscript submitted to J. Hydrol.).

\section{4) RADiATIVE FLUXES}

Incoming solar radiation $R_{s}^{\downarrow}$ measurements at the land surface are used in Eq. (2) to estimate net radiation. The downward longwave radiative flux from the atmosphere above $R_{\text {ad }}$ and the upward longwave radiative flux from the land surface beneath $R_{\mathrm{gu}}$ enter the atmospheric boundary layer (Fig. 1). The expressions for $R_{\mathrm{ad}}$ and $R_{\mathrm{gu}}$ can be found in Brubaker and Entekhabi (1995). Only a portion of the entrainment longwave radiative fluxes from the free atmosphere and land surface $\left(R_{\mathrm{ad}}+R_{\mathrm{gu}}\right)$ is absorbed by the ABL, which is dependent on the mixed-layer bulk emissivity $\varepsilon_{m}$ that itself is a function of the ABL specific humidity. The expression for $\varepsilon_{m}$ can be found in Kim and Entekhabi (1998b).

The ABL cools down by emitting radiative fluxes from within the mixed-layer downward and upward $\left(R_{\mathrm{Ad}}\right.$ and $\left.R_{\mathrm{Au}}\right)$. The formulations for the upward and downward longwave radiative fluxes originating from within the mixed layer can be found in Brubaker and Entekhabi (1995) and Margulis and Entekhabi (2001).

\section{VDA scheme}

The VDA system finds optimal values of $C_{\mathrm{HN}}$ and $\mathrm{EF}$ by minimizing an objective function, which consists of the potential temperature and specific humidity misfit terms, deviations of unknown parameters $\left(C_{\mathrm{HN}}\right.$ and $\left.\mathrm{EF}\right)$ from their prior values, and adjoints. The objective function is formulated as

$$
\begin{aligned}
J\left(\theta, q, \lambda_{1}, \lambda_{2}, R, \mathrm{EF}\right)= & \sum_{i=1}^{N} \int_{t_{o}}^{t_{1}}\left[\theta_{i}(t)-\theta_{\mathrm{SL}, i}(t)\right]^{\mathrm{T}} \mathbf{R}_{\theta}^{-1}\left[\theta_{i}(t)-\theta_{\mathrm{SL}, i}(t)\right] d t+\sum_{i=1}^{N} \int_{t_{o}}^{t_{1}}\left[q_{i}(t)-q_{\mathrm{SL}, i}(t)\right]^{\mathrm{T}} \mathbf{R}_{q}^{-1}\left[q_{i}(t)-q_{\mathrm{SL}, i}(t)\right] d t \\
& +\left(R-R^{\prime}\right)^{\mathrm{T}} \mathbf{B}_{R}^{-1}\left(R-R^{\prime}\right)+\sum_{i=1}^{N}\left(\mathrm{EF}_{i}-\mathrm{EF}_{i}^{\prime}\right)^{\mathrm{T}} \mathbf{B}_{\mathrm{EF}}^{-1}\left(\mathrm{EF}_{i}-\mathrm{EF}_{i}^{\prime}\right) \\
& +\sum_{i=1}^{N} \int_{t_{o}}^{t_{1}} \lambda_{1 i}(t)\left[\rho c_{p} h_{i}(t) \frac{d \theta_{i}(t)}{d t}-\left(R_{\mathrm{ad}}+R_{\mathrm{gu}}\right) \varepsilon_{m}+R_{\mathrm{Ad}}+R_{\mathrm{Au}}-H-H_{\mathrm{top}}\right] d t \\
& +\sum_{i=1}^{N} \int_{t_{o}}^{t_{1}} \lambda_{2 i}(t)\left[\rho h_{i}(t) L_{v} \frac{d q_{i}(t)}{d t}-\mathrm{LE}-\mathrm{LE}_{\mathrm{top}}\right] d t
\end{aligned}
$$

where $R$ is related to the neutral bulk heat transfer via $C_{\mathrm{HN}}=e^{R}$. This transformation is done to make $C_{\mathrm{HN}}$ strictly positive. The variable $N$ is the number of days in the assimilation period (here taken as $N=30$ ). The range $\left[t_{o}, t_{1}\right]=[0900,1600 \mathrm{LT}]$ constitutes the assimilation window in which EF is assumed to be constant. The first and second terms on the right-hand side of Eq. (9) represent the square of misfit between the top of the surface layer potential temperature $\theta_{\mathrm{SL}}$ and specific humidity $q_{\mathrm{SL}}$, and the corresponding estimates (i.e., $\theta$ and $q$ ) from Eqs. (5a) and (5b) over the whole assimilation period. The $\theta_{\mathrm{SL}}$ and $q_{\mathrm{SL}}$ are obtained from $\theta_{a}$ and $q_{a}$ via MOST (see appendix B). Hence, the assimilated screen-level values (i.e., $\theta_{a}$ and $q_{a}$ ) are directly related to the mixed-layer ones (i.e., $\theta_{\mathrm{SL}}$ and $q_{\mathrm{SL}}$ ) through a correction using MOST. The terms $\mathbf{R}_{\theta}^{-1}$ and $\mathbf{R}_{q}^{-1}$ are the 

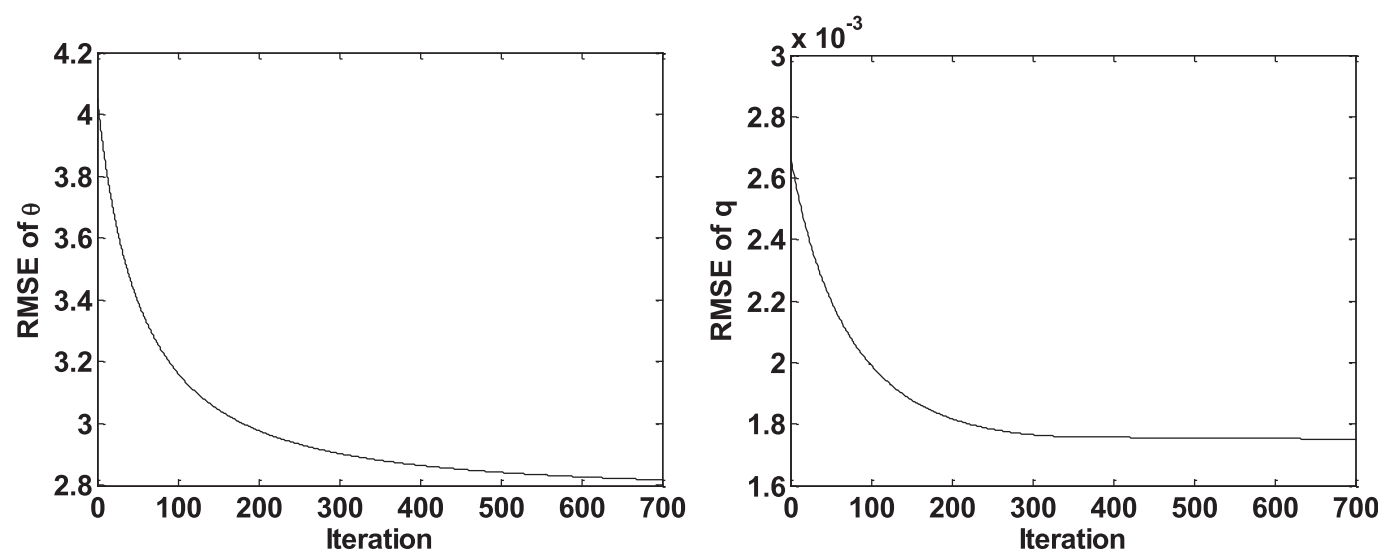

FIG. 2. RMSE of $\theta$ and $q$ estimates vs the iteration number.

inverse error covariance matrices of observation errors of $\theta$ and $q$, respectively. The third and fourth terms respectively express the error of unknown parameters $R$ and $\mathrm{EF}$ with respect to their prior values $\left(R^{\prime}\right.$ and $\left.\mathrm{EF}^{\prime}\right)$. The terms $\mathbf{B}_{R}^{-1}$ and $\mathbf{B}_{\mathrm{EF}}^{-1}$ are the inverse background error covariance matrices of $R$ and $\mathrm{EF}$, respectively. The physical constraints in the last two terms are adjoined to the objective function via the Lagrange multipliers $\lambda_{1}$ and $\lambda_{2}$.

The values of $\mathbf{R}_{\theta}^{-1}, \mathbf{R}_{q}^{-1}, \mathbf{B}_{R}^{-1}$, and $\mathbf{B}_{\mathrm{EF}}^{-1}$ can be obtained from the inverse covariance functions of states (i.e., $\theta$ and $q$ ) and parameters (i.e., $R$ and $\mathrm{EF}$ ), if their statistical structures are known (Bennett 1992). Due to the lack of detailed knowledge about the statistical structure of the states and parameters, $\mathbf{R}_{\theta}^{-1}, \mathbf{R}_{q}^{-1}, \mathbf{B}_{R}^{-1}$, and $\mathbf{B}_{\mathrm{EF}}^{-1}$ are herein regarded as diagonal matrices of numerically constant values whose relative magnitudes control the rate of convergence and the stability of the VDA approach (Bennett 1992; Castelli et al. 1999).

The magnitudes of the diagonal elements in $\mathbf{R}_{\theta}^{-1}$ and $\mathbf{R}_{q}^{-1}$ are respectively set to $10^{-1} \mathrm{~K}^{-2}$ and $10^{5}\left(\mathrm{~kg} \mathrm{~kg}^{-1}\right)^{-2}$ to make the order of magnitude of the first and second terms similar. The absolute value of $\left[\theta(t)-\theta_{\mathrm{SL}}(t)\right]$ has an order of magnitude of $\sim 5 \mathrm{~K}$ \{i.e., $\left[\theta(t)-\theta_{\mathrm{SL}}(t)\right] \sim O(5)$ \}, and thus $\left[\theta_{i}(t)-\theta_{\mathrm{SL}, i}(t)\right]^{T}\left[\theta_{i}(t)-\theta_{\mathrm{SL}, i}(t)\right] \sim O(25)$. The order of magnitude of $\left[q(t)-q_{\mathrm{SL}}(t)\right]$ is $\sim 0.005\left(\mathrm{~kg} \mathrm{~kg}^{-1}\right)$ \{i.e., $\left.\left[q(t)-q_{\mathrm{SL}}(t)\right] \sim O(0.005)\right\}$, and therefore $[q(t)-$ $\left.q_{\mathrm{SL}}(t)\right]^{T}\left[q(t)-q_{\mathrm{SL}}(t)\right] \sim O\left(25 \times 10^{-6}\right)$. With $10^{-1} \mathrm{~K}^{-2}$ and $10^{5}\left(\mathrm{~kg} \mathrm{~kg}^{-1}\right)^{-2}$ as the diagonal elements of $\mathbf{R}_{\theta}^{-1}$ and $\mathbf{R}_{q}^{-1}$, both $\sum_{i=1}^{N} \int_{t_{o}}^{t_{1}}\left[\theta_{i}(t)-\theta_{\mathrm{SL}, i}(t)\right]^{\mathrm{T}} \mathbf{R}_{\theta}^{-1}\left[\theta_{i}(t)-\theta_{\mathrm{SL}, i}(t)\right] d t$ and $\sum_{i=1}^{N} \int_{t_{o}}^{t_{1}}\left[q_{i}(t)-q_{\mathrm{SL}, i}(t)\right]^{\mathrm{T},} \mathbf{R}_{q}^{-1}\left[q_{i}(t)-q_{\mathrm{SL}, i}(t)\right] d t$ have an order of magnitude of $\sim 2.5$. The terms $\mathbf{B}_{R}^{-1}$ and $\mathbf{B}_{\mathrm{EF}}^{-1}$ are obtained through trial and error by assessing their impact on the magnitude of the objective function $J$ (Daley 1991; Castelli et al. 1999). In the first trial, the diagonal elements of $\mathbf{B}_{R}^{-1}$ and $\mathbf{B}_{\mathrm{EF}}^{-1}$ are chosen to be equal and varied from $10^{3}$ to $10^{17}$. The VDA system is unstable for $\mathbf{B}_{R}^{-1}=\mathbf{B}_{\mathrm{EF}}^{-1}$ values from $10^{3}$ to $10^{5}$, and the objective function is minimized for $\mathbf{B}_{R}^{-1}=\mathbf{B}_{\mathrm{EF}}^{-1}=10^{8}$ (Table 1, top). Thereafter, unequal values for $\mathbf{B}_{R}^{-1}$ and $\mathbf{B}_{\mathrm{EF}}^{-1}$ are chosen (Table 1, bottom). After some trials, the minimum value of $0.83 \times 10^{6}$ is obtained for $J$ when the diagonal arrays of $\mathbf{B}_{R}^{-1}$ and $\mathbf{B}_{\mathrm{EF}}^{-1}$ are set to $10^{8}$ and $10^{9}$, respectively. As the last step of our trial, $\mathbf{R}_{\theta}^{-1}$ and $\mathbf{R}_{q}^{-1}$ are increased 10 times, and are set to $1 \mathrm{~K}^{-2}$ and $10^{6}\left(\mathrm{~kg} \mathrm{~kg}^{-1}\right)^{-2}$, respectively. It is observed that the same results can be obtained if $\mathbf{B}_{R}^{-1}$ and $\mathbf{B}_{\mathrm{EF}}^{-1}$ are increased with the same rate (i.e., 10 times). A similar trial-and-error approach was used in Castelli et al. (1999), Caparrini et al. (2003), Bateni et al. (2013a, 2014), and Tajfar et al. (2019, manuscript submitted to J. Hydrol.) to determine the inverse error covariance matrices of states and variables.

To minimize the objective function $J$, its first variation with respect to the independent variables $\theta, q, \lambda_{1}, \lambda_{2}, R$, and EF should be set to zero. Taking the first variation of $J(\delta J)$ with respect to $\theta, q, \lambda_{1}, \lambda_{2}, R$, and $\mathrm{EF}$, grouping them based on $\delta \theta, \delta q, \delta \lambda_{1}, \delta \lambda_{2}, \delta R$, and $\delta \mathrm{EF}$, and finally setting them to zero leads to a set of equations (the so-called Euler-Lagrange equations), which should be solved simultaneously. The Euler-Lagrange equations are presented in appendix $\mathrm{C}$.

Figure 2 indicates the root-mean-square error (RMSE) of potential temperature and specific humidity estimates from the VDA approach versus the iteration number. As anticipated, the RMSEs of $\theta$ and $q$ reduce as the iteration number increases and reach the asymptotic values of $2.82 \mathrm{~K}$ and $1.75 \times 10^{-3} \mathrm{~kg} \mathrm{~kg}^{-1}$, respectively, at the iteration of 700. The decrease in the RMSEs of $\theta$ and $q$ estimates shows the improvement in the model performance as the iteration number grows. In fact, the developed VDA system finds the optimal $\mathrm{EF}$ and $C_{\mathrm{HN}}$ values by minimizing the misfit between $\theta$ and $q$ estimates and observations. 


\section{FIFE dataset}

The VDA approach was tested at the FIFE site. FIFE was carried out on the Konza Prairie in central Kansas from 1987 to 1989. The ground measurements were collected at 32 sites within the Konza Prairie Natural Research Area, a $15 \mathrm{~km} \times 15 \mathrm{~km}$ grassland site that is centered at $39.05^{\circ} \mathrm{N}, 96.53^{\circ} \mathrm{W}$.

Betts and Ball (1998) produced three different datasets from the raw data in FIFE. Two of them are the land surface temperature (LST), and atmospheric forcing data (at the screen level of $2 \mathrm{~m}$ ) including air temperature and humidity, wind speed, and incoming solar radiation, which are averaged over the FIFE site. To do so, they cleaned up the surface meteorological data collected from 10 portable automatic meteorological (PAM) stations, and excluded unrealistic data by applying range filters to the time series. The third dataset is a site-averaged surface heat fluxes time series with a 30 -min time step collected from 22 stations in 1987 and 10 in 1988. The FIFE dataset provides us with nearly continuous (30-min interval) and fairly precise LST, forcings, and fluxes over the diurnal cycle. The vegetation height measurements at the FIFE site are downloaded from the Oak Ridge National Laboratory Distributed Active Archive Center (ORNL DAAC; https://daac.ornl.gov/FIFE/ guides/Vegetation_Biophysical_Data.html).

The radiosonde measurements of potential temperature $\theta$, specific humidity $q$, and mixed-layer height $h$ at the FIFE site are also available to verify the model estimates. These radiosonde measurements were conducted during intensive field campaigns (IFCs) $1-3$ in the summer of 1987 (Strebel et al. 1994). The radiosonde data include 0-8 launches between sunrise and sunset on specific days during the IFCs at roughly 90-min intervals and during the growth phase of the boundary layer (0900-1600 LT). From each IFC, some cloud-free days were chosen to verify the model estimates with the radiosonde data (IFC 1: 4-6 June, IFC 2: 26 June, 6 July, 11 July, IFC 3: 15-17 August). However, because of the nature of radiosonde sampling, the observations are not necessarily representative of the spatial average over the site. This makes the comparison between the model estimates and measurements difficult (Margulis 2002).

Micrometeorological data (i.e., air temperature and humidity, wind speed, and incoming solar radiation), vegetation height, and LST measurements are required to run the VDA model.

The initial ABL height $h\left(t_{o}\right)$ is needed to integrate Eq. (6a) forward in time, and find the evolution of ABL height. The initial ABL height typically varies from
100 to $500 \mathrm{~m}$ (Margulis and Entekhabi 2001; Gentine et al. 2016). Similarly, the magnitudes of $\gamma_{\theta}$ and $\gamma_{q}$ as well as the initial conditions for $\delta_{\theta}$ and $\delta_{q}$ [i.e., $\delta_{\theta}\left(t_{o}\right)$ and $\delta_{q}\left(t_{o}\right)$ ] are required to find the evolution of $\delta_{\theta}$ and $\delta_{q}$. According to Margulis (2002), Van Heerwaarden et al. (2010), and Gentine et al. (2016), $\gamma_{\theta}, \gamma_{q}, \delta_{\theta}$, and $\delta_{q}$ vary over the range of $2-8 \mathrm{~K} \mathrm{~km}^{-1}$, from $-7 \times 10^{-3}$ to $-0.5 \times 10^{-3} \mathrm{~kg} \mathrm{~kg}^{-1} \mathrm{~km}^{-1}$, $2-6 \mathrm{~K}$, and from $-4.8 \times 10^{-3}$ to $-0.5 \times 10^{-3} \mathrm{~kg} \mathrm{~kg}^{-1}$, respectively. In this study, $h\left(t_{o}\right), \gamma_{\theta}, \gamma_{q}, \delta_{\theta}\left(t_{o}\right)$, and $\delta_{q}\left(t_{o}\right)$ are changed from 100 to $500 \mathrm{~m}$, from 2 to $8 \mathrm{~K} \mathrm{~km}^{-1}$, from $-7 \times 10^{-3}$ to $-0.5 \times 10^{-3} \mathrm{~kg} \mathrm{~kg}^{-1} \mathrm{~km}^{-1}$, from 2 to $6 \mathrm{~K}$, and from $-4.8 \times 10^{-3}$ to $-0.5 \times 10^{-3} \mathrm{~kg} \mathrm{~kg}^{-1}$ with an increment of $100 \mathrm{~m}, 0.5 \mathrm{~K} \mathrm{~km}^{-1}, 0.5 \times 10^{-3} \mathrm{~kg} \mathrm{~kg}^{-1} \mathrm{~km}^{-1}$, $0.4 \mathrm{~K}$, and $0.4 \times 10^{-3} \mathrm{~kg} \mathrm{~kg}^{-1}$, respectively. The cost function $J$ reaches its minimum value with $h\left(t_{o}\right), \gamma_{\theta}, \gamma_{q}, \delta_{\theta}\left(t_{o}\right)$, and $\delta_{q}\left(t_{o}\right)$ of $400 \mathrm{~m}, 4.5 \mathrm{~K} \mathrm{~km}^{-1},-1 \times 10^{-3} \mathrm{~kg} \mathrm{~kg}^{-1} \mathrm{~km}^{-1}$, $3.6 \mathrm{~K}$, and $-4.4 \times 10^{-3} \mathrm{~kg} \mathrm{~kg}^{-1}$, respectively.

Following Betts and Ball (1998), albedo $\alpha$ is set to 0.2. A typical value of 0.98 is used for the surface emissivity $\varepsilon_{s}$ (Bateni et al. 2013a). All of the fixed-value parameters used in the VDA approach are listed in Table 2.

The surface heat fluxes measurements and radiosonde observations are used to validate the surface heat fluxes retrievals as well as ABL height, potential temperature, and specific humidity estimates. In addition, the areaaveraged measurements from FIFE dataset give us this opportunity to verify the VDA model over large-scale domains with a computational grid size of a few kilometers (Chen et al. 1996). In this paper, we tested our VDA model in summer 1987 (days 148-243) and 1988 (days 160-243).

\section{Results}

$\mathrm{EF}$ is assumed to be constant during the assimilation window $\left(t_{0}=0900 \mathrm{LT}\right.$ and $\left.t_{1}=1600 \mathrm{LT}\right)$ and is obtained on a daily time scale. Here, $R$ is mostly affected by landscape characteristics, changes on a longer time scale, and is estimated on a monthly basis. The VDA system becomes ill posed if the two parameters (EF and $R$ ) are allowed to vary on the same time scale. The reason for this problem can be explained by rewriting Eq. (5b) as follows:

$$
\begin{aligned}
\rho h L_{v} \frac{d q}{d t} & =\mathrm{LE}+\mathrm{LE}_{\text {top }}=\frac{\mathrm{EF}}{1-\mathrm{EF}} H+\mathrm{LE}_{\text {top }} \\
& =\frac{\mathrm{EF}}{1-\mathrm{EF}} \rho c_{p} e^{R} f(\mathrm{Ri}) u_{a}\left(T-T_{a}\right)+\mathrm{LE}_{\text {top }} .
\end{aligned}
$$

The product of $e^{R}$ and $\mathrm{EF}(1-\mathrm{EF})^{-1}$ appears in Eq. (10). The VDA approach is not able to separate the two unknown parameters (EF and $R$ ) and distinguish their difference if they are allowed to change on the same time scale. To make the estimation problem well posed 
TABLE 1. The magnitude of cost function $J$ for different values of $\mathbf{B}_{R}^{-1}$ and $\mathbf{B}_{\mathrm{EF}}^{-1}$. Equal (top half of table) and unequal (bottom half of table) values for $\mathbf{B}_{R}^{-1}$ and $\mathbf{B}_{\mathrm{EF}}^{-1}$ are considered. The bold font indicates the magnitude of the $\mathbf{B}_{R}^{-1}$ and $\mathbf{B}_{\mathrm{EF}}^{-1}$ that minimized the objective function $J$ for equal and unequal values of $\mathbf{B}_{R}^{-1}$ and $\mathbf{B}_{\mathrm{EF}}^{-1}$.

\begin{tabular}{lccccccccc}
\hline \hline $\mathbf{B}_{R}^{-1}$ & $10^{6}$ & $10^{7}$ & $\mathbf{1 0}^{8}$ & $10^{9}$ & $10^{10}$ & $10^{11}$ & $10^{12}$ & $10^{14}$ & $10^{17}$ \\
$\mathbf{B}_{\mathrm{EF}}^{-1}$ & $10^{6}$ & $10^{7}$ & $\mathbf{1 0}^{8}$ & $10^{9}$ & $10^{10}$ & $10^{11}$ & $10^{12}$ & $10^{14}$ & $10^{17}$ \\
$J \times 10^{6}$ & 1.237 & 1.233 & $\mathbf{1 . 1 5 5}$ & 1.901 & 1.912 & 1.460 & 1.539 & 1.548 \\
$\mathbf{B}_{R}^{-1}$ & $10^{6}$ & $10^{7}$ & $10^{8}$ & $\mathbf{1 0}^{8}$ & $10^{9}$ & $10^{9}$ & $10^{10}$ & $10^{12}$ \\
$\mathbf{B}_{\mathrm{EF}}^{-1}$ & $10^{7}$ & $10^{8}$ & $10^{7}$ & $\mathbf{1 0}^{9}$ & $10^{8}$ & $10^{10}$ & $10^{9}$ & $10^{17}$ \\
$J \times 10^{6}$ & 1.233 & 1.155 & 1.233 & $\mathbf{0 . 8 3 0}$ & 1.183 & 1.882 & 1.954 & 1.539 & 1.548 \\
\hline
\end{tabular}

and realizing that EF and $R$ change on different time sales, daily EF and monthly $R$ are estimated in the VDA approach.

To find a reasonable initial guess for $C_{\mathrm{HN}}=e^{R}$ in each monthly assimilation period, the VDA approach is run for a number of $R$ values ( $R$ is varied from -7.5 to -3.5 with an increment of 0.5 ). Thereafter, for each utilized $R$ value in the VDA approach, the RMSEs of corresponding EF, $\theta$, and $q$ estimates are obtained (Fig. 3). As shown, there is a minimum in the RMSEs of EF, $\theta$, and $q$ estimates, which occurs at the $R$ value of $-4.5,-5.0$, and -5.0 for the first (Julian days 148-177), second (Julian days 178-207), and third (Julian days 208-243) assimilation periods in FIFE 1987 (FIFE 87), respectively. Similarly, the minimum in the RMSEs of EF, $\theta$, and $q$ retrievals happens at the $R$ of $-6.0,-5.5,-5.5$ for the first (Julian days 160-189), second (Julian days 190-219), and third (Julian days 220-243) assimilation periods in FIFE 1988 (FIFE 88). For each period, the $R$ value that leads to the lowest RMSEs of EF, $\theta$, and $q$ estimates is used as the initial guess in the VDA approach. The VDA approach iteratively improves the initial $R$, and finds its optimum value (see appendix $\mathrm{C}$ ).
Table 3 shows the estimated $C_{\mathrm{HN}}$ values from the VDA model for FIFE 87 and 88. Leaf area index (LAI) values are also indicated in Table 3 , which are obtained from the LAI-NDVI (normalized difference vegetation index) exponential relationship proposed by Aparicio et al. (2000) and the site-averaged NDVI data from the Landsat and SPOT satellites presented by Hall et al. (1992). The estimated $C_{\mathrm{HN}}$ values fall within a physically accepted range (Stull 1994; Caparrini et al. 2004a). The changes in the $C_{\mathrm{HN}}$ estimates are consistent with the variations in LAI although no information on vegetation dynamics is used in the VDA approach. It should be noted that the rainfall patterns, and consequently the crop growth and vegetation phenology are different in summer of 1987 and 1988. The FIFE site was wet in the beginning of summer of 1987 , followed by a drydown toward the end of summer. As a result, LAI values decreased during the summer of 1987. Remarkably, the estimated $C_{\mathrm{HN}}$ values decline as the summer progresses. There was a different trend in the canopy phenology in FIFE 88, and LAI grew gradually during the summer of 1988. An increasing pattern in the $C_{\mathrm{HN}}$ values can be seen accordingly.

TABLE 2. Values of time-invariant parameters used in the VDA approach.

\begin{tabular}{|c|c|c|}
\hline Parameter & Value & Unit \\
\hline Air density $(\rho)$ & 1.2 & $\mathrm{~kg} \mathrm{~m}^{-3}$ \\
\hline Specific heat capacity $\left(c_{p}\right)$ & 1004 & $\mathrm{~J} \mathrm{~kg}^{-1} \mathrm{~K}^{-1}$ \\
\hline Stefan-Boltzmann constant $(\sigma)$ & $5.67 \times 10^{-8}$ & $\mathrm{~W} \mathrm{~K}-4 \mathrm{~m}^{-2}$ \\
\hline Latent heat of vaporization $\left(L_{v}\right)$ & $2.5 \times 10^{6}$ & $\mathrm{~J} \mathrm{~kg}^{-1}$ \\
\hline Lapse rate of $\theta$ above $h\left(\gamma_{\theta}\right)$ & 4.5 & $\mathrm{~K} \mathrm{~km}^{-1}$ \\
\hline Lapse rate of $q$ above $h\left(\gamma_{q}\right)$ & $-1.0 \times 10^{-3}$ & $\mathrm{~kg} \mathrm{~kg}^{-1} \mathrm{~km}^{-1}$ \\
\hline Initial ABL height $\left[h\left(t_{o}=0900 \mathrm{LT}\right)\right]$ & 400 & $\mathrm{~m}$ \\
\hline Initial inversion strength of $\theta\left[\delta_{\theta}\left(t_{o}=0900 \mathrm{LT}\right)\right]$ & 3.6 & $\mathrm{~K}$ \\
\hline Initial inversion strength of $q\left[\delta_{q}\left(t_{o}=0900 \mathrm{LT}\right)\right]$ & $-4.4 \times 10^{-3}$ & $\mathrm{~kg} \mathrm{~kg}^{-1}$ \\
\hline Gas constant for dry air $\left(R_{d}\right)$ & 287 & $\mathrm{~J} \mathrm{~kg}^{-1{ }^{\circ} \mathrm{C}^{-1}}$ \\
\hline Gas constant for water vapor $\left(R_{v}\right)$ & 461 & $\mathrm{~J} \mathrm{~kg}^{-1{ }^{\circ} \mathrm{C}^{-1}}$ \\
\hline Surface pressure $\left(P_{s}\right)$ & 96700 & $\mathrm{~Pa}$ \\
\hline Mechanical turbulence dissipation & 0.01 & $\mathrm{~m}^{-1}$ \\
\hline Assimilation window $\left[t_{o}, t_{1}\right]$ & {$[0900,1600 \mathrm{LT}]$} & $\mathrm{h}$ \\
\hline Surface emissivity $\left(\varepsilon_{s}\right)$ & 0.98 & - \\
\hline Albedo $(\alpha)$ & 0.2 & - \\
\hline von Kármán constant $(k)$ & 0.41 & - \\
\hline Entrainment parameter $(A)[$ Eq. $(8 \mathrm{a})]$ & 0.2 & - \\
\hline Number of days in the assimilation period $(N)$ & 30 & - \\
\hline
\end{tabular}



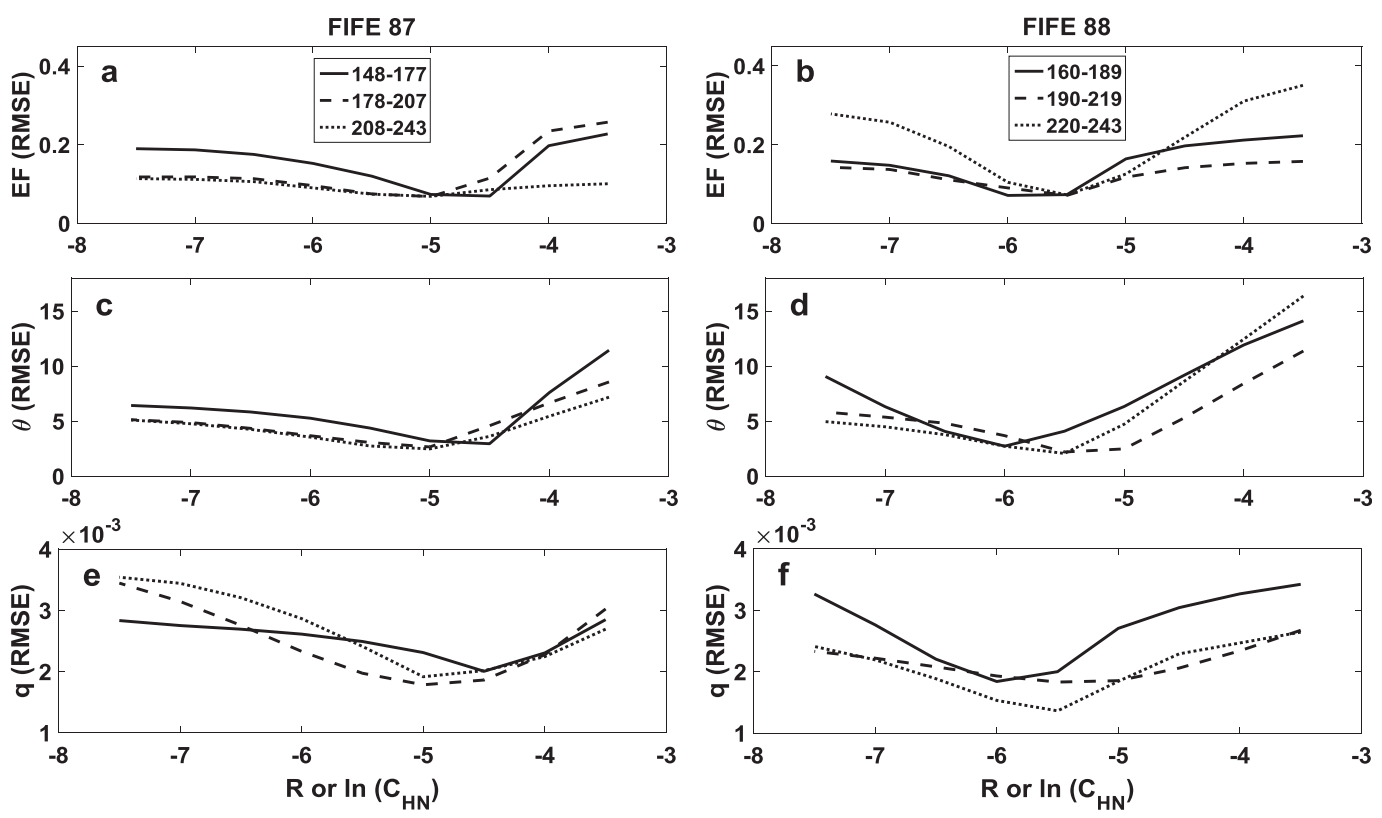

FIG. 3. RMSE of estimated (a),(b) EF, (c),(d) ABL potential temperature, and (e),(f) specific humidity for different $R$ values.

The estimated daily EF values from the VDA approach (solid lines) are compared with the observations (open circles) in Fig. 4. As shown, there is a good agreement between the measured and estimated EF values. The EF estimates show a distinct response to drydown and wetting events although no soil moisture or rainfall information is utilized in the assimilation approach. For example, the EF estimates can capture the drydown period (days 197-216 in 1987) and the wetting periods (days 195-199 and 226-231 in 1988). The results show that the assimilation system is able to extract the implicit information in the sequences of screen-level air temperature and specific humidity to partition available energy between the turbulent heat fluxes.

The half-hourly estimates of sensible and latent heat fluxes from the VDA approach are plotted versus observations in Fig. 5 for FIFE 87 and 88. As can be seen, the $H$ and LE estimations are mainly scattered around the $45^{\circ}$ line, showing a fairly good agreement with the measurements. For FIFE 1987 (1988), the RMSE is $38.61 \mathrm{~W} \mathrm{~m}^{-2}\left(48.42 \mathrm{~W} \mathrm{~m}^{-2}\right)$ for half-hourly sensible heat flux, and $89.05 \mathrm{~W} \mathrm{~m}^{-2}\left(86.63 \mathrm{~W} \mathrm{~m}^{-2}\right)$ for half-hourly latent heat flux. For FIFE 1987 (1988), the half-hourly $H$ and LE estimates have a mean absolute error (MAE) of $31.37\left(37.55 \mathrm{~W} \mathrm{~m}^{-2}\right)$ and $70.95 \mathrm{~W} \mathrm{~m}^{-2}\left(66.84 \mathrm{~W} \mathrm{~m}^{-2}\right)$, respectively. The results indicate that the proposed VDA approach can take advantage of the implicit information in the sequences of screen-level air temperature and specific humidity to estimate sensible and latent heat fluxes.
According to Eq. (3), the error in the estimated $H$ values mainly depends on the uncertainty in the estimation of air temperature and $C_{\mathrm{HN}}$. Equation (4) indicates that the error in LE estimates is dependent on the uncertainty of not only $H$ but also EF estimates. The RMSE of LE estimates is higher than that of $H$ because the errors in the air temperature, $C_{\mathrm{HN}}$, and EF estimates directly propagate into the LE retrievals. The uncertainty of air temperature, $C_{\mathrm{HN}}$, and EF estimates is due to the structural model errors, errors due to uncertainty in the initial conditions for Eq. (5a) and (5b) and lapse rates in potential temperature and specific humidity above the mixed layer as well as simplistic assumptions of constant daily EF and monthly $C_{\mathrm{HN}}$, insignificant advection, and convectively well mixed boundary layer, which results in constant profiles of potential temperature and specific humidity with height (Fig. 1).

The VDA system finds the optimum values of $C_{\mathrm{HN}}$ and $\mathrm{EF}$ by minimizing the difference between the ABL potential temperature and specific humidity estimates

TABLE 3. Estimated neutral bulk heat transfer coefficient $C_{\mathrm{HN}}$ values by the VDA model for FIFE 87 and 88 .

\begin{tabular}{ccccccc}
\hline \hline \multicolumn{3}{c}{ FIFE 87} & & & \multicolumn{3}{c}{ FIFE 88 } \\
\cline { 1 - 2 } \cline { 6 - 8 } Julian days & $C_{\text {HN }}$ & LAI & & Julian days & $C_{\text {HN }}$ & LAI \\
\hline $148-177$ & 0.0093 & 1.7 & & $160-189$ & 0.0024 & 1.2 \\
$178-207$ & 0.0079 & 1.2 & & $190-219$ & 0.0040 & 1.3 \\
$208-243$ & 0.0057 & 1.1 & & $220-243$ & 0.0042 & 1.4 \\
\hline
\end{tabular}



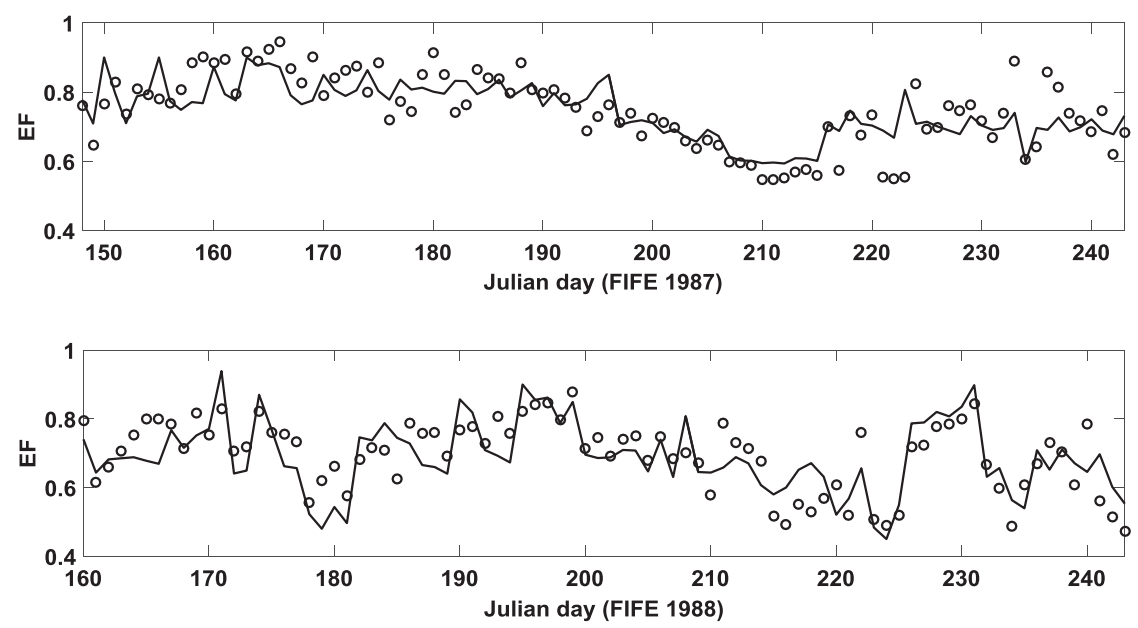

FIG. 4. Time series of evaporative fraction for (top) FIFE 87 and (bottom) FIFE 88 [estimated evaporative fraction from measured heat fluxes (circles) and the VDA approach (solid lines)].

from Eqs. (5a) and (5b) (i.e., $\theta$ and $q$ ), and the corresponding values obtained from the screen-level air temperature and specific humidity via MOST (i.e., $\theta_{\mathrm{SL}}$ and $\left.q_{\mathrm{SL}}\right)$. Figure 6 shows half-hourly estimated ABL potential temperature and specific humidity from
Eqs. (5a) and (5b) versus corresponding retrievals from air temperature and specific humidity for FIFE 87 and 88. The close agreement indicates that the data assimilation approach can successfully update the two main unknowns of the problem $\left(C_{\mathrm{HN}}\right.$ and $\left.\mathrm{EF}\right)$ and finally
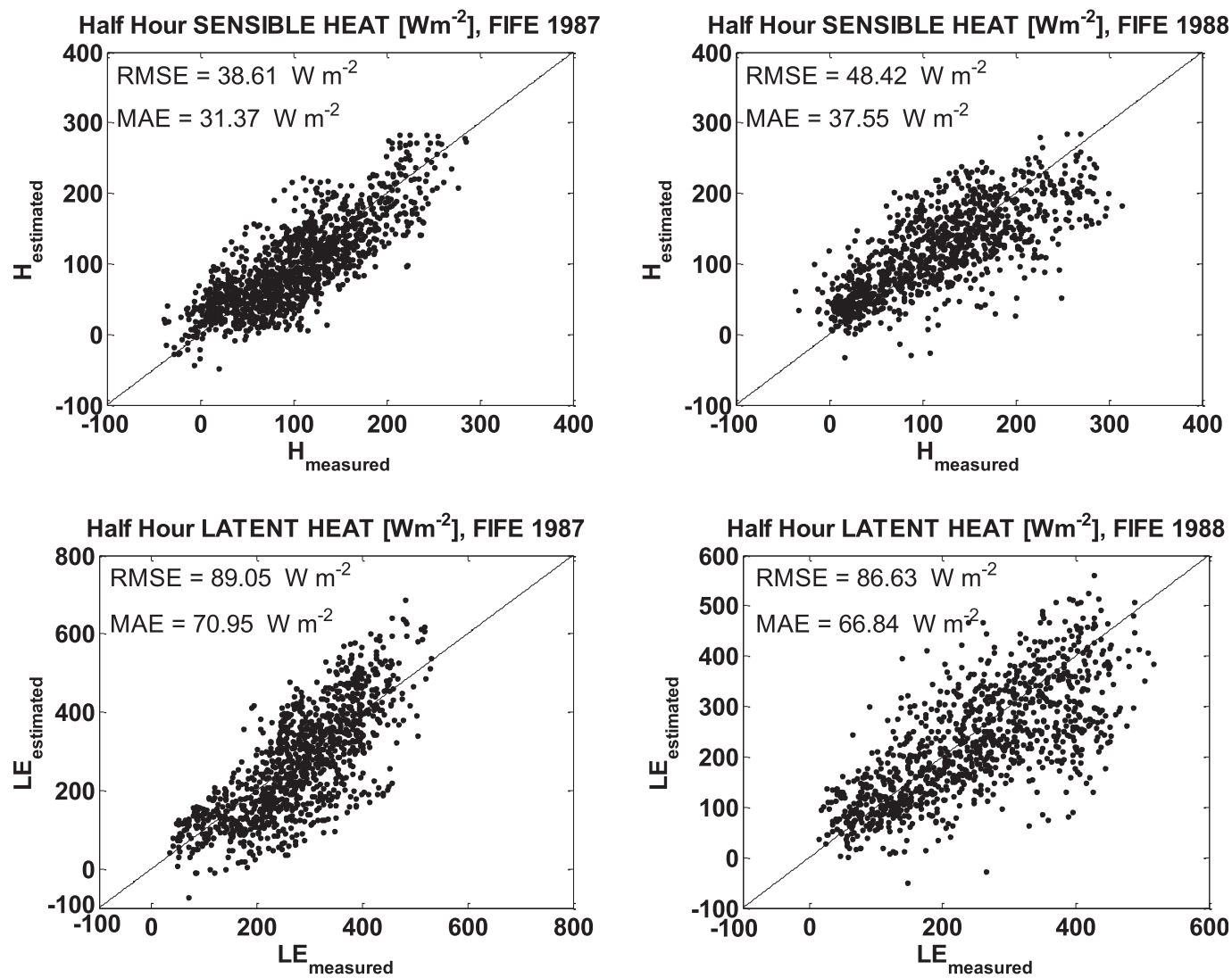

FIG. 5. Scatterplot of half-hourly estimated vs measured (top) sensible and (bottom) latent heat fluxes for (left) FIFE 87 and (right) FIFE 88. 

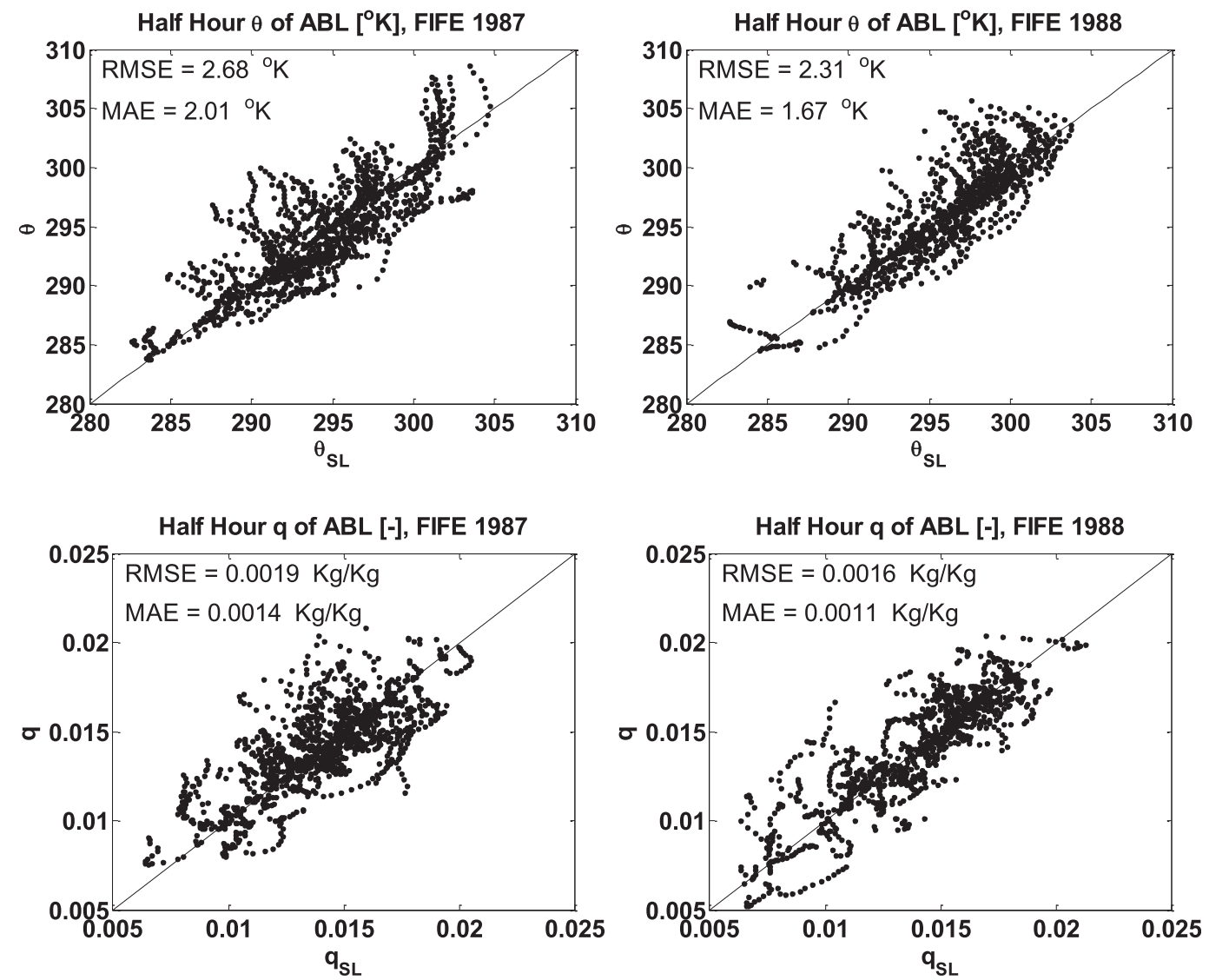

FIG. 6. Scatterplot of half-hourly estimated (top) potential temperature and (bottom) specific humidity vs corresponding observations for (left) FIFE 87 and (right) FIFE 88.

obtain their optimal values. For FIFE 87 (88), the potential temperature and specific humidity estimates have an RMSE of $2.68 \mathrm{~K}(2.31 \mathrm{~K})$ and $0.0019 \mathrm{~kg} \mathrm{~kg}^{-1}$ $\left(0.0016 \mathrm{~kg} \mathrm{~kg}^{-1}\right)$, respectively.

Time series of daily averaged estimated and measured turbulent heat fluxes are shown in Figs. 7 and 8 for FIFE 87 and 88 , respectively. As indicated, the magnitude and day-to-day fluctuations of the estimated sensible and latent heat fluxes correspond relatively well with those of the observations. For example, the estimated sensible heat flux can capture the rising pattern in observations during the drydown period (Julian days 197-216) in 1987. The MAE of daily $H$ and LE estimates are respectively $22.11\left(23.65 \mathrm{~W} \mathrm{~m}^{-2}\right)$ and $44.39 \mathrm{~W} \mathrm{~m}^{-2}$ $\left(42.93 \mathrm{~W} \mathrm{~m}^{-2}\right)$ for FIFE 87 (88). The estimated daily $H$ and LE have RMSE of $25.72\left(27.77 \mathrm{~W} \mathrm{~m}^{-2}\right)$ and $53.63 \mathrm{~W} \mathrm{~m}^{-2}\left(48.22 \mathrm{~W} \mathrm{~m}^{-2}\right)$ for FIFE 87 (88). Overall, the results indicate that the VDA approach can effectively use the information contained in the screen-level air temperature and specific humidity and retrieve the turbulent heat fluxes.

Figure 9 compares time series of estimated half-hourly sensible and latent heat fluxes with the observations for
Julian days 178-207 (FIFE 87). As can be seen, the turbulent heat fluxes estimates from the VDA approach are reasonably accurate, and for most of the days the magnitude and phase of $H$ and LE retrievals agree well with the observations. The discrepancy between the $H$ and LE estimates and observations is due to the simplifying assumptions including constant monthly $C_{\mathrm{HN}}$, constant daily $\mathrm{EF}$, and convectively well mixed boundary layer, which results in constant profiles of potential temperature and specific humidity with height.

The RMSEs of half-hourly and daily average turbulent heat fluxes estimates from the proposed VDA approach (that assimilate sequences of screen-level air temperature and specific humidity measurements) are compared to those of Caparrini et al. (2004a), Bateni and Entekhabi (2012b), and Bateni et al. (2013a) (that assimilated sequences of LST observations) in Table 4. Our results are roughly comparable to those of Caparrini et al. (2004a), Bateni and Entekhabi (2012b), and Bateni et al. (2013a), implying that the developed VDA can use the implicit information in the time series of screenlevel air temperature and specific humidity to partition 

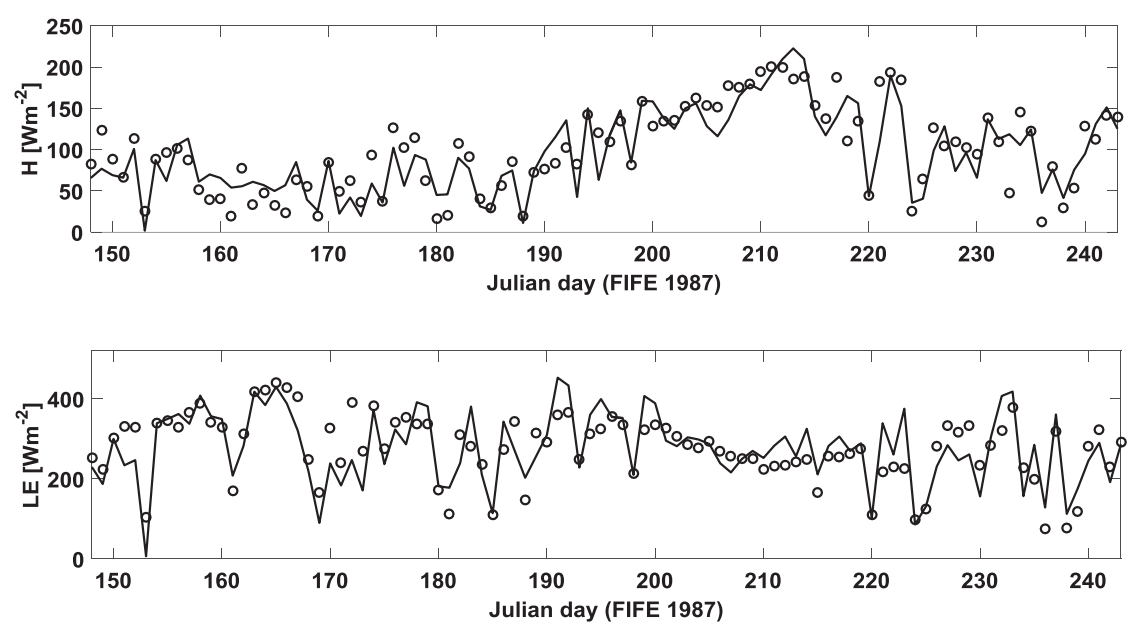

FIG. 7. Time series of observed (circles) and predicted (solid lines) daily turbulent heat fluxes from the VDA approach for FIFE 87: (top) sensible and (bottom) latent heat fluxes.

the available energy between the sensible and latent heat fluxes.

Figure 10 compares the mean diurnal cycles of measured and estimated SEB components over the whole modeling period (i.e., Julian days $148-243$ for FIFE 87 and $160-243$ for FIFE 88 ). The term $G$ is calculated as the residual of the surface energy balance equation [Eq. (1)]. As indicated, the phases of mean diurnal cycles of estimated $R_{n}, H$, and LE agree reasonably well with those of observations. However, there is a significant difference between the diurnal cycles of estimated and observed ground heat flux. This happens because the phase of $G$ is directly related to that of the soil temperature gradient via $G=-\left.p(d T / d Z)\right|_{z=0}$, while the developed VDA approach does not assimilate the sequences of LST observations. Hence, future studies should be directed toward assimilating sequences of
LST observations in addition to the screen-level air temperature and specific humidity measurements. This can be done by incorporating the soil heat diffusion equation (as a constraint) into the proposed VDA system, and assimilating LST observations into it.

The results show that assimilating the state variables of atmosphere (i.e., air temperature and specific humidity) can estimate not only the magnitude of $H, \mathrm{LE}$, and $R_{n}$, but also their diurnal cycle (phase). The phase of $G$ is directly related to that of LST via $G=-p d T / d z$. The developed VDA approach does not assimilate the sequences of LST, and thus it cannot capture the diurnal cycle of ground heat flux. Hence, there is a significant difference between the diurnal cycles of estimated and observed ground heat flux. In FIFE 87 (88), the VDA approach slightly overestimates (underestimates) net radiation. This may be due to the errors in the estimates
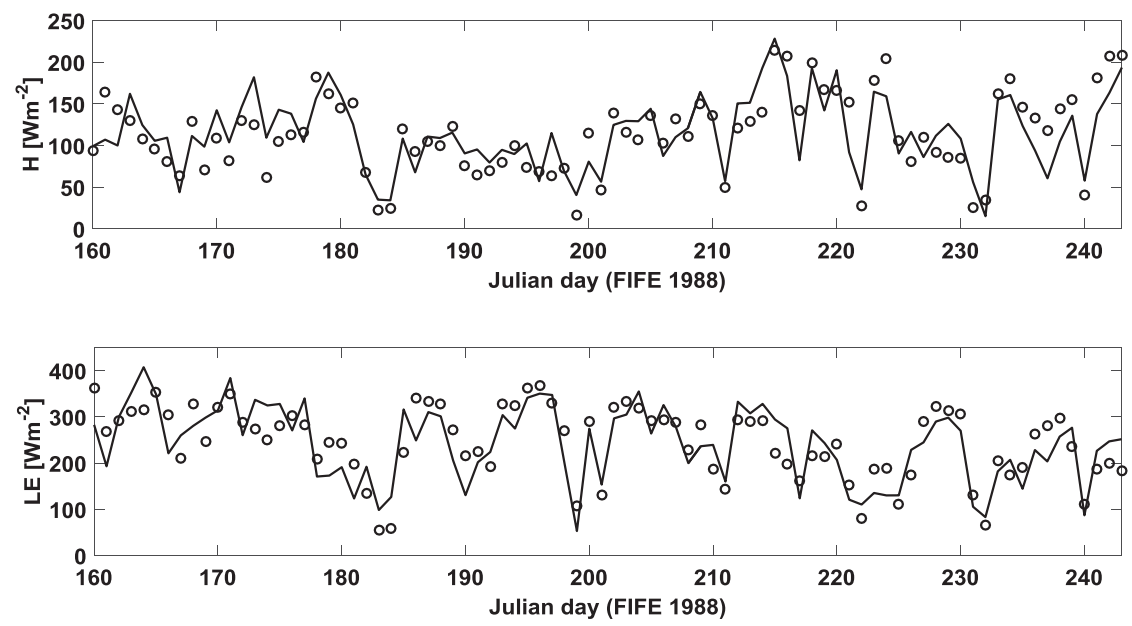

FIG. 8. As in Fig. 7, but for FIFE 88. 

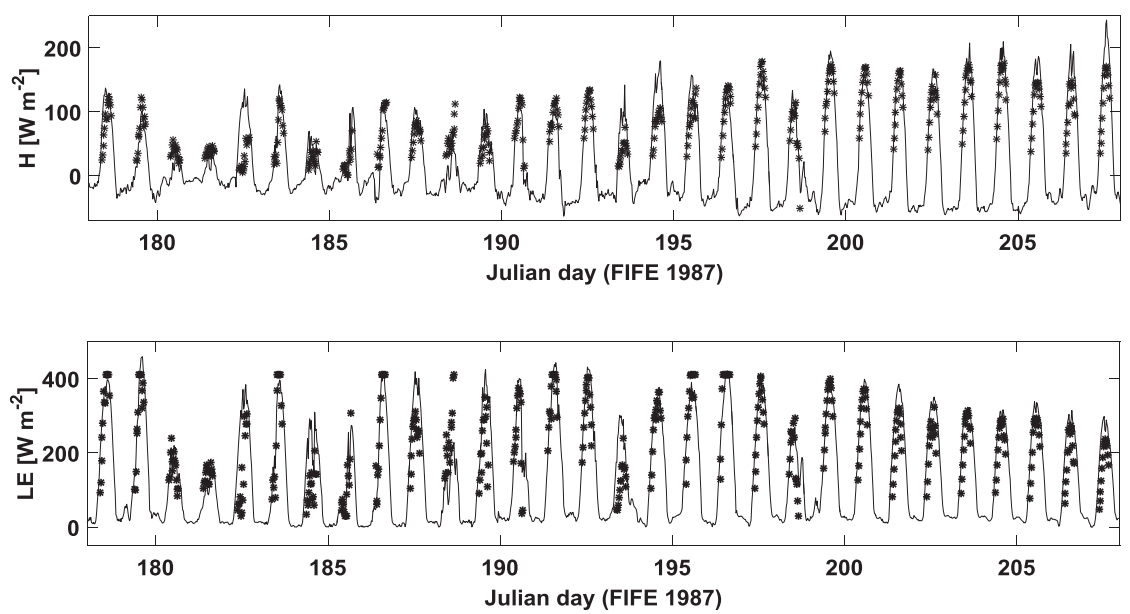

FIG. 9. Time series of measured (symbols) and estimated (lines) half-hourly turbulent fluxes for Julian days 178-207: (top) sensible heat flux and (bottom) latent heat flux.

ABL potential temperature values that transfer into the air temperature estimates, ultimately causing uncertainties in the net radiation retrievals.

As mentioned before, the $h\left(t_{o}\right), \gamma_{\theta}, \gamma_{q}, \delta_{\theta}\left(t_{o}\right)$, and $\delta_{q}\left(t_{o}\right)$ values that lead to a minimum cost function are used in the VDA system. However, the radiosonde data at the FIFE site provide a unique opportunity to run the VDA approach with the measured $h\left(t_{o}\right), \gamma_{\theta}, \gamma_{q}, \delta_{\theta}\left(t_{o}\right)$, and $\delta_{q}\left(t_{o}\right)$ values. Figure 11 compares the $H$ and LE estimates using the optimized and measured $h\left(t_{o}\right), \gamma_{\theta}$, $\gamma_{q}, \delta_{\theta}\left(t_{o}\right)$, and $\delta_{q}\left(t_{o}\right)$ values on Julian days $155,156,176$, 177, 178, 187, 227, 228, and 229. As expected, utilizing the $h\left(t_{o}\right), \gamma_{\theta}, \gamma_{q}, \delta_{\theta}\left(t_{o}\right)$, and $\delta_{q}\left(t_{o}\right)$ measurements in the VDA approach (instead of the optimized values) improves the $H$ and LE estimates, and decreases the MAE and RMSE of daily $H$ estimates by $16.12 \%$ and $15.21 \%$, respectively (see Table 5). Similarly, the MAE (RMSE) of daily LE estimates reduces from 48.62 to $40.44 \mathrm{~W} \mathrm{~m}^{-2}$ (from 54.19 to $46.94 \mathrm{~W} \mathrm{~m}^{-2}$ ). However, this improvement is not significant (about 15\%), implying that the VDA can provide reasonably accurate $H$ and LE estimates by using the tuned $h\left(t_{o}\right), \gamma_{\theta}, \gamma_{q}, \delta_{\theta}\left(t_{o}\right)$, and $\delta_{q}\left(t_{o}\right)$ values.

The ABL observations based on radiosonde profiles of potential temperature, specific humidity, and mixed-layer height at the FIFE site during the summer of 1987 were used to verify the estimations. Figures 12a-i compares the mixed-layer height $h$, potential temperature $\theta$, and specific humidity $q$ estimates from the VDA approach with those inferred from the radiosondes for 15-17 August. The error bars represent the standard deviations of the measurements from radiosondes. As indicated, in general, the estimated $h, \theta$ and $q$ are reasonably close to the radiosonde observations. On 15 August, there is an increasing trend in $h, \theta$, and $q$, which is captured by the corresponding estimates. On 16 August, the ABL height and potential temperature grow throughout the day, while the ABL specific humidity diminishes. Remarkably, the VDA estimates capture

TABLE 4. Comparing the RMSEs of half-hourly and daily average $H$ and LE estimates from this study (that assimilates sequences of reference-level air temperature and humidity observations) with those of Caparrini et al. (2004a), Bateni and Entekhabi (2012b), and Bateni et al. (2013a) (that assimilated sequences of LST observations) for FIFE 87 and 88.

\begin{tabular}{|c|c|c|c|c|}
\hline & \multicolumn{2}{|c|}{ FIFE 87} & \multicolumn{2}{|c|}{ FIFE 88} \\
\hline & $H\left(\mathrm{~W} \mathrm{~m}^{-2}\right)$ & $\operatorname{LE}\left(\mathrm{W} \mathrm{m}^{-2}\right)$ & $H\left(\mathrm{~W} \mathrm{~m}^{-2}\right)$ & $\operatorname{LE}\left(\mathrm{W} \mathrm{m}^{-2}\right)$ \\
\hline \multicolumn{5}{|c|}{ Half-hourly } \\
\hline Caparrini et al. (2004a) & 63.21 & 102.80 & 47.95 & 76.31 \\
\hline Bateni and Entekhabi (2012b) & 44.87 & 112.01 & 49.53 & 89.51 \\
\hline Bateni et al. (2013a) & 34.12 & 74.82 & 44.74 & 77.94 \\
\hline This study & 38.61 & 89.05 & 48.42 & 86.63 \\
\hline \multicolumn{5}{|c|}{ Daily average } \\
\hline Caparrini et al. (2004a) & 52.97 & 53.68 & 36.90 & 43.75 \\
\hline Bateni and Entekhabi (2012b) & 31.48 & 61.90 & 30.11 & 50.35 \\
\hline Bateni et al. (2013a) & 23.24 & 49.95 & 22.92 & 42.70 \\
\hline This study & 25.72 & 53.63 & 27.77 & 48.22 \\
\hline
\end{tabular}


FIFE 87

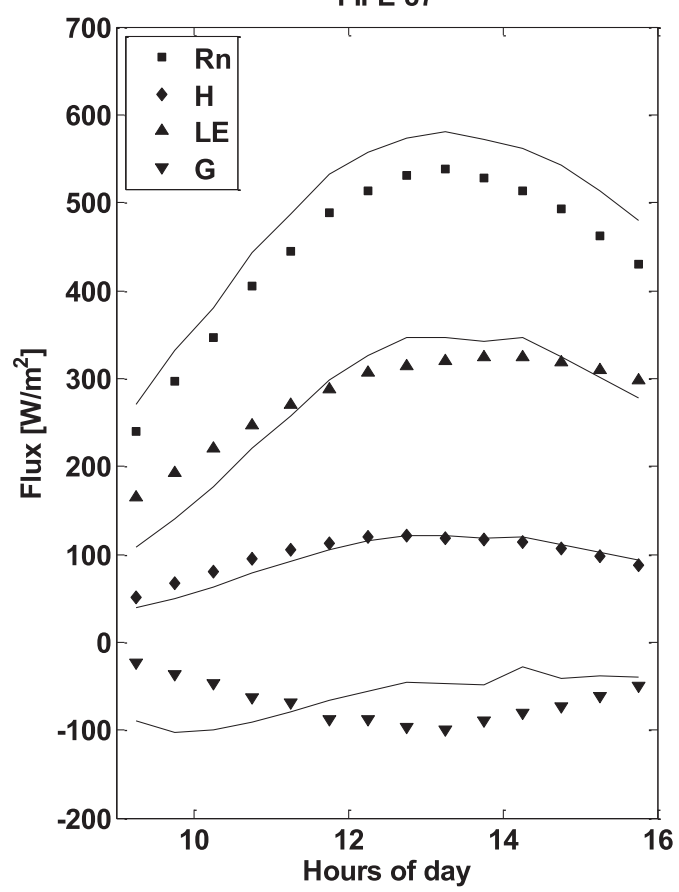

FIFE 88

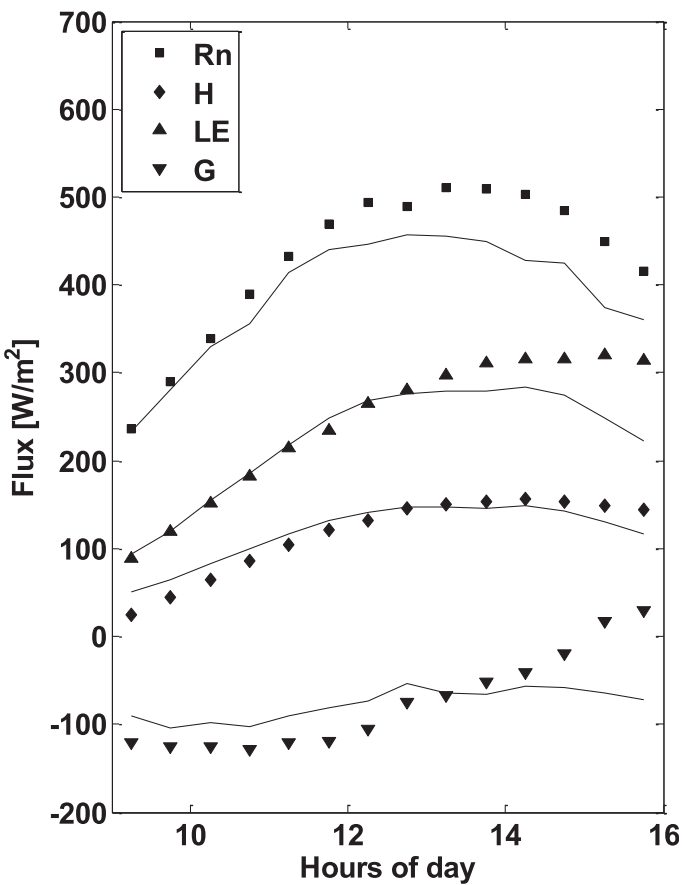

FIG. 10. Diurnal cycle of surface energy balance components for (left) FIFE 87 and (right) 88 showing measurements (symbols) and estimations (solid lines).

both the rising (ABL height and potential temperature) and falling (ABL specific humidity) trends in the radiosonde measurements. Finally, on 17 August, the $\mathrm{ABL} h$ and $\theta$ estimates agree relatively well with the observations and follow their rising trend, while there is a discrepancy between the modeled and observed $q$. The differences between the model estimates and observations from radiosonde data are due to simplistic
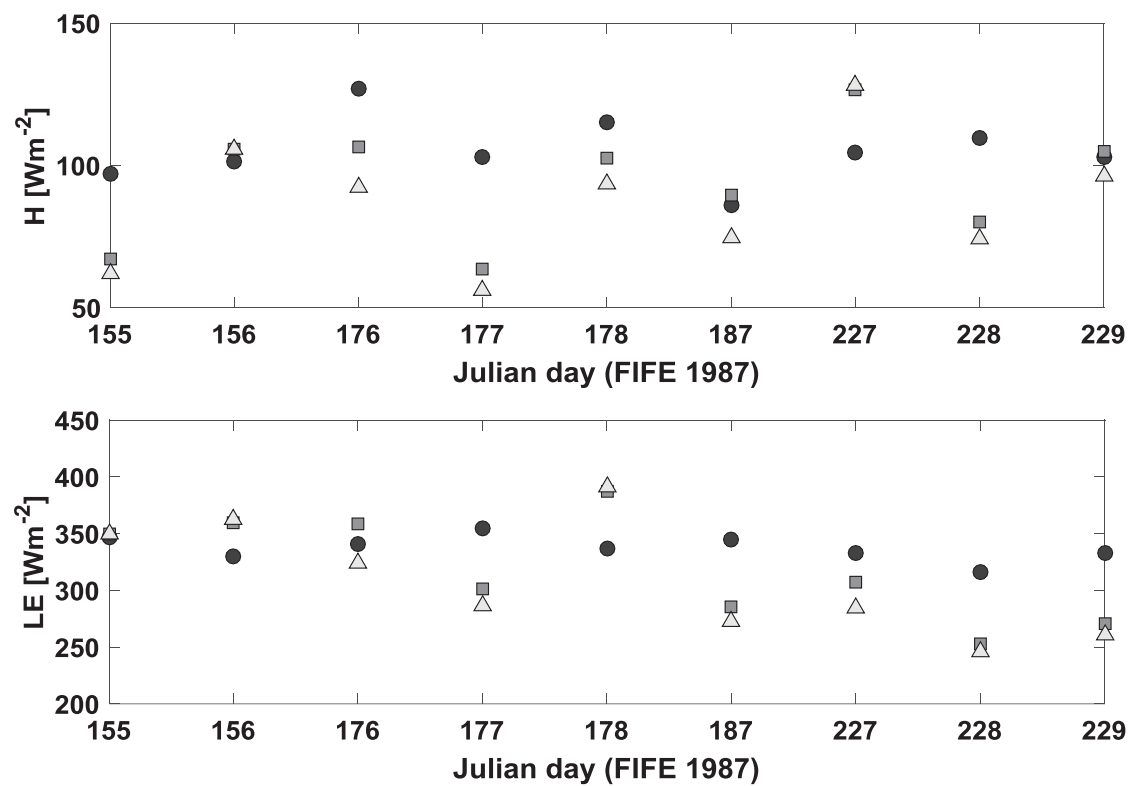

FIG. 11. Comparing the observed and estimated (top) sensible and (bottom) latent heat fluxes for Julian days 155, 156, 176, 177, 178, 187, 227, 228, and 229 in FIFE 87. Circles show observations. Triangles and squares indicate estimated turbulent heat fluxes using the optimized and measured $h\left(t_{o}\right), \gamma_{\theta}, \gamma_{q}, \delta_{\theta}\left(t_{o}\right)$, and $\delta_{q}\left(t_{o}\right)$ values, respectively. 
TABLE 5. Comparing the MAE and RMSE of daily $H$ and LE estimates from the VDA approach, using optimized and measured $h\left(t_{o}\right), \gamma_{\theta}, \gamma_{q}, \delta_{\theta}\left(t_{o}\right)$, and $\delta_{q}\left(t_{o}\right)$ values for Julian days $155,156,176$, 177, 178, 187, 227, 228, and 229 in FIFE 87.

\begin{tabular}{|c|c|c|c|c|}
\hline \multirow[b]{2}{*}{ Different scenarios } & \multicolumn{2}{|c|}{$\begin{array}{c}\text { MAE } \\
\left(\mathrm{W} \mathrm{m}^{-2}\right)\end{array}$} & \multicolumn{2}{|c|}{$\begin{array}{c}\text { RMSE } \\
\left(\mathrm{W} \mathrm{m}^{-2}\right)\end{array}$} \\
\hline & $H$ & LE & $H$ & $\mathrm{LE}$ \\
\hline $\begin{array}{l}\text { Measured } h\left(t_{o}\right), \gamma_{\theta}, \gamma_{q}, \delta_{\theta}\left(t_{o}\right) \text {, } \\
\quad \text { and } \delta_{q}\left(t_{o}\right)\end{array}$ & 19.13 & 40.44 & 22.10 & 46.94 \\
\hline $\begin{array}{l}\text { Optimized } h\left(t_{o}\right), \gamma_{\theta}, \gamma_{q}, \delta_{\theta}\left(t_{o}\right) \text {, } \\
\quad \text { and } \delta_{q}\left(t_{o}\right)\end{array}$ & 24.32 & 48.62 & 28.01 & 54.19 \\
\hline
\end{tabular}

assumptions (e.g., monthly constant $C_{\mathrm{HN}}$, daily constant $\mathrm{EF}$, insignificant advection, etc.), errors in the forcing data, and the fact that the radiosonde point observations may not be able to accurately represent the spatial average for the FIFE site. Similar results were obtained for other cloud free days during the summer of 1987. Herein, for brevity, we presented results for 15-17 August 1987.

\section{Conclusions}

A variational data assimilation (VDA) approach is developed to estimate sensible $(H)$ and latent (LE) heat fluxes by assimilating the screen-level air temperature and humidity into an atmospheric boundary layer model. The unknown parameters of the VDA are evaporative fraction (EF) and neutral bulk heat transfer coefficient $\left(C_{\mathrm{HN}}\right)$. EF represents partitioning between the turbulent heat fluxes and $C_{\mathrm{HN}}$ scales the sum of turbulent heat fluxes.

The developed model is tested at the First International Satellite Land Surface Climatology Project (ISLSCP)
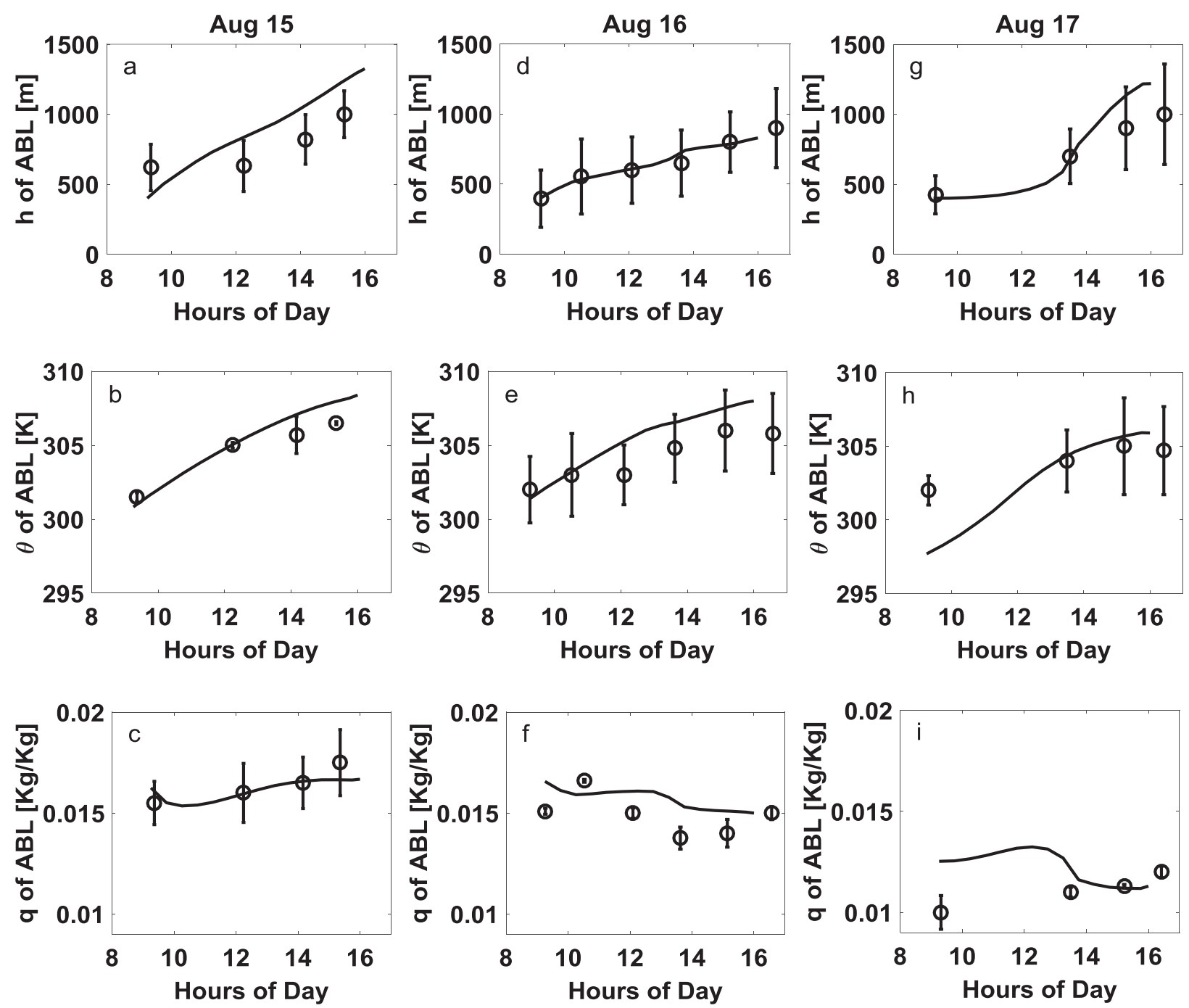

FIG. 12. Diurnal evolution of (top) ABL height, (middle) potential temperature, and (bottom) humidity at the FIFE site for 15-17 Aug 1987. The solid lines indicate the VDA model results, and the open circles mark the mean ABL radiosonde observations with one standard deviation. 
Field Experiment (FIFE) site during summer 1987 and 1988. The results indicate that the developed VDA approach is capable of estimating the unknown parameters (i.e., EF and $C_{\mathrm{HN}}$ ) reasonably well. The changes in the estimated $C_{\mathrm{HN}}$ are consistent with variations in vegetation phenology, and fall within a physically accepted range. The day-to-day fluctuations in the estimated EF are consistent with observations even though no information on precipitation events and soil moisture dynamics is used within the assimilation model.

Comparing the estimated turbulent heat fluxes with measurements over the FIFE site shows that the assimilation of screen-level air temperature and humidity into the developed VDA model can predict the turbulent heat fluxes accurately. For FIFE 1987 (1988), the halfhourly $H$ and LE estimates have a mean absolute error (MAE) of $31.37 \mathrm{~W} \mathrm{~m}^{-2}\left(37.55 \mathrm{~W} \mathrm{~m}^{-2}\right)$ and $70.95 \mathrm{~W} \mathrm{~m}^{-2}$ $\left(66.84 \mathrm{~W} \mathrm{~m}^{-2}\right)$, respectively. The root-mean-square error (RMSE) for half-hourly sensible and latent heat fluxes are $38.61 \mathrm{~W} \mathrm{~m}^{-2}\left(48.42 \mathrm{~W} \mathrm{~m}^{-2}\right)$ and $89.05 \mathrm{~W} \mathrm{~m}^{-2}$ $\left(86.63 \mathrm{~W} \mathrm{~m}^{-2}\right)$, respectively for FIFE 87 (88). The estimated daytime-averaged turbulent heat fluxes are in good agreement with the observations. The MAE of daily averaged $H$ and $\mathrm{LE}$ are $22.11 \mathrm{~W} \mathrm{~m}^{-2}\left(23.65 \mathrm{~W} \mathrm{~m}^{-2}\right)$ and $44.39 \mathrm{~W} \mathrm{~m}^{-2}\left(42.93 \mathrm{~W} \mathrm{~m}^{-2}\right)$ for FIFE 87 (88). The estimated daily $H$ and LE have RMSEs of $25.72 \mathrm{~W} \mathrm{~m}^{-2}$ $\left(27.77 \mathrm{~W} \mathrm{~m}^{-2}\right)$ and $53.63 \mathrm{~W} \mathrm{~m}^{-2}\left(48.22 \mathrm{~W} \mathrm{~m}^{-2}\right)$ for FIFE 87 (88). This agreement between the model predictions and observations indicates the feasibility of proposed model. It is worth mentioning that the simplistic assumptions (e.g., constant daily $\mathrm{EF}$, constant monthly $C_{\mathrm{HN}}$, insignificant advection, uniform profiles of potential temperature and specific humidity within the mixed layer) that are used to build the VDA system generate structural model errors and cause errors in the turbulent heat fluxes estimates.

The mean diurnal cycles of estimated and measured sensible and latent heat fluxes and net radiation are close, implying that the VDA model can robustly capture the phase of $H$, LE, and $R_{n}$. However, there is a significant difference between the diurnal cycle of estimated and measured ground heat flux, and they are out of phase. This is due to the fact that the ground heat flux $G$ is related to the soil temperature gradient through $G=-p d T / d z$ (where $p$ is the soil thermal conductivity, $T$ is the ground temperature, and $z$ is the soil depth), and thus the phase of $G$ is strictly dependent upon that of skin temperature, which is not estimated in our framework. Indeed, the VDA system does not assimilate the sequences of LST and therefore cannot capture the diurnal cycle of ground heat flux.

The mixed-layer height, potential temperature, and specific humidity estimates from the VDA approach are reasonably close to those inferred from radiosondes.
These estimates can also capture the rising/falling trends of observations during the course of the day. Overall, the results show that the developed VDA approach can extract implicit information from sequences of screen-level air temperature and specific humidity measurements to estimate the turbulent heat fluxes and ABL characteristics.

Future studies should focus on 1) the synergistic assimilation of the LST (as the state variable of land surface) as well as the screen-level air temperature and specific humidity (as the state variables of atmosphere) to improve the turbulent heat fluxes and diurnal cycle (phase) of $G, 2)$ testing the developed VDA approach over several sites with contrasting hydrological and vegetative conditions, 3) evaluating the impact of temporal resolution of air temperature and specific humidity data on the performance of the VDA approach, and 4) developing a weak-constraint VDA approach that can capture errors in the turbulent heat fluxes due to advection.

Acknowledgments. This study has been made possible by U.S. Geological Survey (USGS) Grant G16AP00049 (2018AS485BB) and U.S. Department of Agriculture (USDA) Grant 69-3A75-17-54 to the University of Hawai' $i$ at Mānoa. It is a contributed paper of the Water Resources Research Center, University of Hawai'i at Mānoa, Honolulu, Hawaii.

\section{APPENDIX A}

\section{List of Symbols}

$\begin{array}{ll}B & \text { Stanton number }(-) \\ \mathbf{B}_{\mathrm{EF}}^{-1} & \text { Inverse background error covariance of } \mathrm{EF}(-) \\ \mathbf{B}_{R}^{-1} & \text { Inverse background error covariance of } R(-) \\ C_{\mathrm{HN}} & \text { Neutral bulk heat transfer coefficient }(-) \\ c_{p} & \text { Specific heat capacity of dry air }\left(\mathrm{J} \mathrm{kg}^{-1} \mathrm{~K}^{-1}\right) \\ D_{1}, D_{2} & \text { Dissipation of mechanical turbulent energy }\left(\mathrm{m}^{3} \mathrm{~s}^{-3}\right) \\ d & \text { Zero-plane displacement height }(\mathrm{m}) \\ E & \text { Evaporative rate from ground }\left(\mathrm{kg} \mathrm{m}^{-2} \mathrm{~s}^{-1}\right) \\ \mathrm{EF} & \text { Evaporative fraction }(-) \\ f & \text { Atmospheric stability correction function }(-) \\ G & \text { Ground heat flux }\left(\mathrm{W} \mathrm{m}^{-2}\right) \\ G_{*} & \text { Production of mechanical turbulent energy }\left(\mathrm{m}^{3} \mathrm{~s}^{-3}\right) \\ g & \text { Gravitational acceleration }\left(\mathrm{m} \mathrm{s}^{-2}\right) \\ H & \text { Sensible heat flux }\left(\mathrm{W} \mathrm{m} \mathrm{m}^{-2}\right) \\ H_{\mathrm{top}} & \text { Entrainment sensible heat flux }\left(\mathrm{W} \mathrm{m}^{-2}\right) \\ H_{v} & \text { Virtual heat flux }\left(\mathrm{W} \mathrm{m} \mathrm{m}^{-2}\right) \\ h & \text { Mixed-layer height }(\mathrm{m}) \\ J & \text { Objective functional }(-) \\ k & \text { Von Kármán's constant }(-) \\ L & \text { Monin-Obhukov length }(\mathrm{m}) \\ L_{v} & \text { Latent heat of vaporization }\left(\mathrm{J} \mathrm{kg}^{-1}\right)\end{array}$




\begin{tabular}{|c|c|}
\hline LE & Latent heat flux $\left(\mathrm{W} \mathrm{m}^{-2}\right)$ \\
\hline $\mathrm{LE}_{\text {top }}$ & Entrainment latent heat flux $\left(\mathrm{W} \mathrm{m}^{-2}\right)$ \\
\hline LAI & Leaf area index $\left(\mathrm{m}^{2} \mathrm{~m}^{-2}\right)$ \\
\hline$N$ & Number of days in the assimilation period (-) \\
\hline$P_{h}$ & Pressure at height $h(\mathrm{~Pa})$ \\
\hline$P_{s}$ & Surface pressure $(\mathrm{Pa})$ \\
\hline$p$ & Soil thermal conductivity $\left(\mathrm{W} \mathrm{m}^{-1} \mathrm{~K}^{-1}\right)$ \\
\hline 9 & Mixed-layer specific humidity [Eq. (5b)] $\left(\mathrm{kg} \mathrm{kg}^{-1}\right)$ \\
\hline$q_{a}$ & Specific humidity at the screen level $\left(\mathrm{kg} \mathrm{kg}^{-1}\right)$ \\
\hline$q_{\mathrm{SL}}$ & $\begin{array}{l}\text { Specific humidity at the bottom of mixed } \\
\text { layer }\left(\mathrm{kg} \mathrm{kg}^{-1}\right)\end{array}$ \\
\hline$R$ & Transformation variable $(-)$ \\
\hline$R_{\mathrm{Ad}}$ & $\begin{array}{l}\text { Downwelling longwave radiation from within } \\
\text { the mixed layer }\left(\mathrm{W} \mathrm{m}^{-2}\right)\end{array}$ \\
\hline$R_{\mathrm{Au}}$ & $\begin{array}{l}\text { Upwelling longwave radiation from within the } \\
\text { mixed layer }\left(\mathrm{W} \mathrm{m}^{-2}\right)\end{array}$ \\
\hline$R_{\mathrm{ad}}$ & $\begin{array}{l}\text { Downwelling longwave radiation from above } \\
\text { the mixed layer }\left(\mathrm{W} \mathrm{m}^{-2}\right)\end{array}$ \\
\hline$R_{d}$ & Gas constant for dry air $\left(\mathrm{J} \mathrm{kg} \mathrm{K}^{-1}\right)$ \\
\hline$R_{\mathrm{gu}}$ & $\begin{array}{l}\text { Upwelling longwave radiation from ground } \\
\text { into the mixed layer }\left(\mathrm{W} \mathrm{m}^{-2}\right)\end{array}$ \\
\hline$R_{l}^{\downarrow}$ & Incoming longwave radiation $\left(\mathrm{W} \mathrm{m}^{-2}\right)$ \\
\hline$R_{n}$ & Net radiation at the surface $\left(\mathrm{W} \mathrm{m}^{-2}\right)$ \\
\hline$R_{s}^{\downarrow}$ & Incoming solar radiation $\left(\mathrm{W} \mathrm{m}^{-2}\right)$ \\
\hline $\mathbf{R}_{q}^{-1}$ & Inverse error covariance of $q\left(\mathrm{~kg}^{2} \mathrm{~kg}^{-2}\right)$ \\
\hline $\mathbf{R}_{\theta}^{-1}$ & Inverse error covariance of $\theta\left(\mathrm{K}^{-2}\right)$ \\
\hline$T$ & Land surface temperature $(\mathrm{K})$ \\
\hline$T_{a}$ & Screen-level air temperature $(\mathrm{K})$ \\
\hline$t$ & Time (s) \\
\hline$u_{a}$ & Wind speed at the screen level $\left(\mathrm{m} \mathrm{s}^{-1}\right)$ \\
\hline$u_{\mathrm{SL}}$ & Wind speed at the bottom of mixed layer $\left(\mathrm{m} \mathrm{s}^{-1}\right)$ \\
\hline$u_{*}$ & Friction velocity $\left(\mathrm{m} \mathrm{s}^{-1}\right)$ \\
\hline$z$ & Soil depth (m) \\
\hline$z_{0 \mathrm{~h}}$ & Roughness length scales for heat (m) \\
\hline$z_{0 \mathrm{~m}}$ & Roughness length scales for momentum (m) \\
\hline$z_{\mathrm{SL}}$ & Surface-layer height (m) \\
\hline$z_{\text {screen }}$ & Screen-level height $(2 \mathrm{~m})(\mathrm{m})$ \\
\hline$z_{\mathrm{veg}}$ & Vegetation height (m) \\
\hline$\alpha$ & Surface albedo $(-)$ \\
\hline$\delta_{q}$ & Specific humidity inversion strength $\left(\mathrm{kg} \mathrm{kg}^{-1}\right)$ \\
\hline$\delta_{\theta}$ & Potential temperature inversion strength $(\mathrm{K})$ \\
\hline$\epsilon_{a}$ & Atmospheric emissivity $(-)$ \\
\hline$\varepsilon_{\mathrm{ad}}$ & Effective emissivity above the mixed layer (-) \\
\hline$\varepsilon_{d}$ & Effective mixed-layer downward emissivity (-) \\
\hline$\varepsilon_{u}$ & Effective mixed-layer upward emissivity (-) \\
\hline$\varepsilon_{m}$ & Mixed-layer bulk emissivity (一) \\
\hline$\varepsilon_{s}$ & Surface emissivity $(-)$ \\
\hline$\gamma_{q}$ & Lapse rate of $q$ above the mixed layer $\left(\mathrm{kg} \mathrm{kg}^{-1} \mathrm{~m}^{-}\right)$ \\
\hline$\gamma_{\theta}$ & Lapse rate of $\theta$ above the mixed layer $\left(\mathrm{K} \mathrm{m}^{-1}\right)$ \\
\hline$\lambda_{1}, \lambda_{2}$ & Lagrange multipliers (一) \\
\hline$\Psi_{m}$ & Stability function for momentum $(-)$ \\
\hline$\rho$ & Air density $\left(\mathrm{kg} \mathrm{m}^{-3}\right)$ \\
\hline$\sigma$ & Stefan-Boltzmann constant $\left(\mathrm{W} \mathrm{m}^{-2} \mathrm{~K}^{-4}\right)$ \\
\hline
\end{tabular}

$\theta \quad$ Mixed-layer potential temperature [Eq. (5a)] (K)

$\theta_{a} \quad$ Screen-level potential temperature (K)

$\theta_{\mathrm{SL}} \quad$ Potential temperature at the bottom of mixed layer $(\mathrm{K})$

$\varphi \quad$ Mechanical turbulence dissipation parameter (-)

\section{APPENDIX B}

\section{Monin-Obukhov Similarity Theory}

The Monin-Obukhov length $L$ is defined as

$$
L=\frac{-\rho c_{p} \theta_{a}\left(1+\frac{R_{d}}{R_{v}} q_{a}\right) u_{*}^{3}}{k g H},
$$

where $R_{d}$ is the gas constant for dry air, $R_{v}$ is the gas constant for water vapor, $g$ is the gravitational acceleration, $k$ is the von Kármán's constant, $\rho$ is the air density, and $c_{p}$ is the specific heat capacity of air (see Table 2). The term $u_{*}$ is the friction velocity, $H$ is the sensible heat flux, and $q_{a}$ and $\theta_{a}$ are the specific humidity and potential temperature at the screen level, respectively.

The neutral bulk heat transfer coefficient for heat $C_{\mathrm{HN}}$ can be related to the roughness length scale for heat $z_{0 \mathrm{~h}}$ via (Bateni et al. 2013b)

$$
C_{\mathrm{HN}}=\frac{k^{2}}{\ln ^{2}\left(\frac{z_{\text {screen }}}{z_{0 \mathrm{~h}}}\right)-k \mathrm{~B}^{-1} \ln \left(\frac{z_{\text {screen }}}{z_{\text {oh }}}\right)} .
$$

The roughness length scales for heat $z_{0 \mathrm{~h}}$ and momentum $z_{0 \mathrm{~m}}$ are related through (Garratt 1994; Brutsaert 2005; Bateni et al. 2013b)

$$
k B^{-1}=\ln \left(\frac{z_{0 \mathrm{~m}}}{z_{0 \mathrm{~h}}}\right),
$$

where $B$ is the Stanton number.

Duynkerke (1992) related $k B^{-1}$ to the leaf area index (LAI) and friction velocity $u_{*}$ via

$$
k B^{-1}=\left(\frac{-13 u_{*}^{0.4}}{\mathrm{LAI}}+0.85\right)^{-1} .
$$

The friction velocity can be related to the wind speed measurements at the screen level via (Rigden and Salvucci 2015)

$$
u_{*}=\frac{k u_{a}}{\ln \left(\frac{z_{\text {screen }}-d}{z_{0 \mathrm{~m}}}\right)-\Psi_{m}\left(\frac{z_{\text {screen }}-d}{L}\right)+\Psi_{m}\left(\frac{z_{0 \mathrm{~m}}}{L}\right)},
$$


where $u_{a}$ is the wind speed at the screen level, $d$ is the zeroplane displacement height ( $d$ is $2 / 3$ of the vegetation height $z_{\text {veg }}$ ), and $\Psi_{m}$ is the stability function for momentum (see Garratt 1994; Brutsaert 2005; Rigden and Salvucci 2015).

The following algorithm explains how $\theta_{\mathrm{SL}}$ and $q_{\mathrm{SL}}$ are obtained from $\theta_{a}$ and $q_{a}$ :

1) Guess a reasonable value for $u_{*}$.

2) Substitute $u_{*}$ from step 1 in Eq. (B1) to estimate $L$, and Eq. (B4) to estimate $k B^{-1}$.

3) Substitute the $C_{\mathrm{HN}}$ estimate from the VDA approach and obtained $k B^{-1}$ from step 2 in Eq. (B2) to find $z_{0 \mathrm{~h}}$.

4) Substitute $z_{0 \mathrm{~h}}$ from step 3 in Eq. (B3) to find $z_{0 \mathrm{~m}}$.

5) Substitute $z_{0 \mathrm{~m}}$ from step 4 and $L$ from step 2 in Eq. (B5) to find $u_{*}$.

6) Repeat steps $2-5$ until the algorithm converges (i.e., the difference between $u_{*}$ estimates from the last two iterations becomes smaller than $0.01 \mathrm{~m} \mathrm{~s}^{-1}$ ) to the optimal values of $u_{*}, z_{0 \mathrm{~h}}, z_{0 \mathrm{~m}}$, and $L$ for a given $C_{\mathrm{HN}}$ value.

Using the $u_{*}$ and $L$ estimates from step 6 , the potential temperature, specific humidity, and wind speed at the top of the surface layer (i.e., $\theta_{\mathrm{SL}}, q_{\mathrm{SL}}$, and $u_{\mathrm{SL}}$ ) are obtained by expanding $\theta_{a}, q_{a}$, and $u_{a}$ from the screen height $z_{\text {screen }}$ to the bottom of the mixed layer $z_{\mathrm{SL}}\left(z_{\mathrm{SL}} \sim 0.1 \mathrm{~h}\right)$ by Monin-Obukhov Similarity Theory (MOST) (Rigden and Salvucci 2015).

The estimated $\theta_{\mathrm{SL}}$ and $q_{\mathrm{SL}}$ are used to integrate Eqs. (C1) and (C3) backward in time. The estimated $u_{\mathrm{SL}}$ is utilized to integrate Eq. (6a) forward in time. As the potential temperature and specific humidity are invariant through the mixed layer, the initial conditions for Eqs. (5a) and (5b) [i.e., $\theta\left(t=t_{o}\right)$ and $q\left(t=t_{o}\right)$ ] are set to be equal to $\theta_{\mathrm{SL}}\left(t=t_{o}\right)$ and $q_{\mathrm{SL}}\left(t=t_{o}\right)$, respectively. The obtained initial conditions [i.e., $\theta\left(t=t_{o}\right)$ and $q\left(t=t_{o}\right)$ ] are used in appendix $\mathrm{C}$ to solve Eqs. (5a) and (5b) forward in time.

\section{APPENDIX C}

\section{Euler-Lagrange Equations}

The data assimilation approach iteratively improves estimates of $\mathrm{EF}$ and $R$, starting from the initial guesses $\mathrm{EF}^{\prime}$ and $R^{\prime}$. This procedure is done iteratively through the following steps: 1 ) integrate the ABL potential temperature and specific humidity [i.e., Eqs. (5a) and (5b)] forward in time every $30 \mathrm{~min}$ using the initial conditions $\theta\left(t=t_{o}\right)$ and $q\left(t=t_{o}\right)$ [appendix B describes how $\theta\left(t=t_{o}\right)$ and $q\left(t=t_{o}\right)$ are obtained in each iteration], 2) integrate the adjoint models [i.e., Eqs. (C1) and (C3)] backward in time every $30 \mathrm{~min}$ using the final conditions from Eqs. (C2) and (C4), 3) update the parameters EF and $R$ using Eqs. (C5) and (C6) (in the first iteration, $R^{\prime}$ and $\mathrm{EF}^{\prime}$ are obtained by an initial guess; in the next iterations, $R^{\prime}$ and $\mathrm{EF}^{\prime}$ are the corresponding estimates in the previous iteration), and 4) repeating steps $1-3$ until convergence is reached. The equations involved are as follows:

$$
\begin{aligned}
\frac{d \lambda_{1}}{d t} & =\frac{1}{h}\left\{\frac{2 R_{\theta}^{-1}\left(\theta-\theta_{\mathrm{SL}}\right)}{\rho c_{p}}+\lambda_{1}\left[-\frac{4 \theta G_{*} e^{-\varphi h}}{g h \delta_{\theta}}-\frac{0.2 f(\mathrm{Ri}) u_{a}\left(T-T_{a}\right) e^{R}}{\delta_{\theta}}\left(1+\frac{0.07 \mathrm{EF}}{1-\mathrm{EF}}\right)\right.\right. \\
& +\frac{0.2 \theta e^{R} f(\mathrm{Ri}) u_{a}}{\delta_{\theta}}\left(1+\frac{0.07 \mathrm{EF}}{1-\mathrm{EF}}\right)\left(\frac{P_{s}}{P_{h}}\right)^{R_{d} / c_{p}}-\frac{\varepsilon_{m} \varepsilon_{a d} \sigma\left(4 \theta^{3}+12 \theta^{2} \delta \theta+4 \delta \theta^{3}+12 \theta \delta \theta^{2}\right)}{\rho c_{p}}\left(\frac{P_{h}}{P_{s}}\right)^{4 R_{d} / c_{p}}+\frac{4 \varepsilon_{u} \sigma \theta^{3}}{\rho c_{p}} \\
& \left.-\frac{4 \varepsilon_{d} \sigma \theta^{3}}{\rho c_{p}}+1.32 e^{R} f(\mathrm{Ri}) u_{a}\left(\frac{P_{s}}{P_{h}}\right)^{R_{d} / c_{p}}\right]+\lambda_{2}\left[-\frac{2 q}{c_{p}} \frac{G_{*} e^{-\varphi h}}{g h \delta_{\theta}}+\frac{0.2 q e^{R} f(\mathrm{Ri}) u_{a}}{c_{p} \delta_{\theta}}\left(\frac{P_{s}}{P_{h}}\right)^{R_{d} / c_{p}}\left(1+\frac{0.07 \mathrm{EF}}{1-\mathrm{EF}}\right)\right. \\
& \left.\left.+\frac{\mathrm{EF} e^{R} f(\mathrm{Ri}) u_{a}}{(1-\mathrm{EF}) L_{v}}\left(\frac{P_{s}}{P_{h}}\right)^{R_{d} / c_{p}}-\frac{\delta_{q}}{c_{p}} \frac{2 G_{*} e^{-\varphi h}}{g h \delta_{\theta}}+\frac{0.2 \delta_{q}}{c_{p} \delta_{\theta}} e^{R} f(\mathrm{Ri}) u_{a}\left(\frac{P_{s}}{P_{h}}\right)^{R_{d} / c_{p}}\left(1+\frac{0.07 \mathrm{EF}}{1-\mathrm{EF}}\right)\right]\right\},
\end{aligned}
$$

$$
\lambda_{1}\left(t_{1}\right)=0,
$$

$$
\begin{aligned}
\frac{d \lambda_{2}}{d t}= & \frac{1}{h}\left[\frac{2 R_{q}^{-1}\left(q-q_{\mathrm{SL}}\right)}{\rho}-\frac{2 \lambda_{2} \theta G_{*} e^{-\varphi h}}{g h \delta_{\theta}}\right. \\
& \left.-\frac{0.2 \lambda_{2} e^{R} f(\mathrm{Ri}) u_{a}\left(T-T_{a}\right)}{\delta_{\theta}}\left(1+\frac{0.07 \mathrm{EF}}{1-\mathrm{EF}}\right)\right],
\end{aligned}
$$

$$
\lambda_{2}\left(t_{1}\right)=0
$$




$$
\begin{aligned}
\mathrm{EF}_{i}= & \frac{1}{2 \mathbf{B}_{\mathrm{EF}}^{-1}} \int_{t_{0}}^{t_{1}}\left[\frac{0.07 \lambda_{1} \theta \rho c_{p} e^{R} f(\mathrm{Ri}) u_{a}\left(T-T_{a}\right)}{(1-\mathrm{EF})^{2}} \times \frac{0.2}{\delta_{\theta}}+\frac{0.07 \lambda_{2} \rho q e^{R} f(\mathrm{Ri}) u_{a}\left(T-T_{a}\right)}{(1-\mathrm{EF})^{2}} \times \frac{0.2}{\delta_{\theta}}\right. \\
& \left.+\frac{\lambda_{2} \rho c_{p} e^{R} f(\mathrm{Ri}) u_{a}\left(T-T_{a}\right)}{L_{v}(1-\mathrm{EF})^{2}}+\frac{0.07 \lambda_{2} \rho \delta_{q} e^{R} f(\mathrm{Ri}) u_{a}\left(T-T_{a}\right)}{(1-\mathrm{EF})^{2}} \times \frac{0.2}{\delta_{\theta}}\right] d t+\mathrm{EF}_{i}^{\prime}, \quad \text { and } \\
R= & \frac{1}{2 \mathbf{B}_{R}^{-1}} \sum \int_{t_{0}}^{t_{1}}\left[\left(1+\frac{0.07 \mathrm{EF}}{1-\mathrm{EF}}\right) \times \frac{0.2 \lambda_{1} \theta \rho c_{p} e^{R} f(\mathrm{Ri}) u_{a}\left(T-T_{a}\right)}{\delta_{\theta}}+1.32 \lambda_{1} \rho c_{p} e^{R} f(\mathrm{Ri}) u_{a}\left(T-T_{a}\right)\right. \\
& +\left(1+\frac{0.07 \mathrm{EF}}{1-\mathrm{EF}}\right) \times \frac{0.2 \lambda_{2} \rho q e^{R} f(\mathrm{Ri}) u_{a}\left(T-T_{a}\right)}{\delta_{\theta}}+\frac{\mathrm{EF}_{2} \rho c_{p} e^{R} f(\mathrm{Ri}) u_{a}\left(T-T_{a}\right)}{(1-\mathrm{EF}) L_{v}}+\left(1+\frac{0.07 \mathrm{EF}}{1-\mathrm{EF}}\right) \\
& \left.\times \frac{0.2 \lambda_{2} \rho \delta_{q} e^{R} f(\mathrm{Ri}) u_{a}\left(T-T_{a}\right)}{\delta_{\theta}}\right] d t+R^{\prime} .
\end{aligned}
$$

\section{REFERENCES}

Abdolghafoorian, A., and L. Farhadi, 2016: Uncertainty quantification in land surface hydrologic modeling: Toward an integrated variational data assimilation framework. IEEE J. Sel. Top. Appl. Earth Obs. Remote Sens., 9, 2628-2637, https://doi.org/ 10.1109/JSTARS.2016.2553444.

— land surface moisture and temperature via a variational data assimilation framework. Water Resour. Res., 55, 4648-4667, https://doi.org/10.1029/2018WR024580.

,-- S. M. Bateni, S. Margulis, and T. Xu, 2017: Characterizing the effect of vegetation dynamics on the bulk heat transfer coefficient to improve variational estimation of surface turbulent fluxes. J. Hydrometeor., 18, 321-333, https://doi.org/10.1175/ JHM-D-16-0097.1.

Alapaty, K., N. L. Seaman, D. S. Niyogi, and A. F. Hanna, 2001: Assimilating surface data to improve the accuracy of atmospheric boundary layer simulations. J. Appl. Meteor., 40, 2068-2082, https:// doi.org/10.1175/1520-0450(2001)040<2068:ASDTIT>2.0.CO;2.

Aparicio, N., D. Villegas, J. Casadesús, J. L. Araus, and C. Royo, 2000: Spectral vegetation indices as nondestructive tools for determining durum wheat yield. Agron. J., 92, 83-91, https:// doi.org/10.2134/agronj2000.92183x.

Bagley, J. E., A. R. Desai, P. C. West, and J. A. Foley, 2011: A simple, minimal parameter model for predicting the influence of changing land cover on the land-atmosphere system. Earth Interact., 15, https://doi.org/10.1175/2011EI394.1.

Balsamo, G., J. F. Mahfouf, S. Belair, and G. Deblonde, 2007: A land data assimilation system for soil moisture and temperature: An information content study. J. Hydrometeor., 8, 12251242, https://doi.org/10.1175/2007JHM819.1.

Bateni, S. M., and D. Entekhabi, 2012a: Relative efficiency of land surface energy balance components. Water Resour. Res., 48, W04510, https://doi.org/10.1029/2011WR011357.

$\longrightarrow$, and — 2012b: Surface heat flux estimation with the ensemble Kalman smoother: Joint estimation of state and parameters. Water Resour. Res., 48, W08521, https://doi.org/ 10.1029/2011WR011542.

- — - , and D.-S. Jeng, 2013a: Variational assimilation of land surface temperature and the estimation of surface energy balance components. J. Hydrol., 481, 143-156, https://doi.org/ 10.1016/j.jhydrol.2012.12.039.
,-- , and F. Castelli, 2013b: Mapping evaporation and estimation of surface control of evaporation using remotely sensed land surface temperature from a constellation of satellites. Water Resour. Res., 49, 950-968, https://doi.org/ 10.1002/wrcr.20071.

,$- \ldots$, S. Margulis, F. Castelli, and L. Kergoat, 2014: Coupled estimation of surface heat fluxes and vegetation dynamics from remotely sensed land surface temperature and fraction of photosynthetically active radiation. Water Resour. Res., 50, 8420-8440, https://doi.org/10.1002/2013WR014573.

Bennett, A. F., 1992: Inverse Methods in Physical Oceanography. Cambridge University Press, $346 \mathrm{pp}$.

Betts, A. K., and J. H. Ball, 1998: FIFE surface climate and site-average dataset 1987-89. J. Atmos. Sci., 55, 1091-1108, https://doi.org/ 10.1175/1520-0469(1998)055<1091:FSCASA > 2.0.CO;2.

Bouttier, F., J. F. Mahfouf, and J. Noilhan, 1993a: Sequential assimilation of soil moisture from atmospheric low-level parameters. Part I: Sensitivity and calibration studies. J. Appl. Meteor., 32, 1335-1351, https://doi.org/10.1175/15200450(1993)032<1335:SAOSMF > 2.0.CO;2.

,-- , and,$- 1993 \mathrm{~b}$ : Sequential assimilation of soil moisture from atmospheric low-level parameters. II: Implementation in a mesoscale model. J. Appl. Meteor., 32, 1352-1364, https://doi.org/10.1175/1520-0450(1993)032<1352:SAOSMF> 2.0.CO;2.

Brenner, C., C. E. Thiem, H. Wizemann, M. Bernhardi, and K. Schulz, 2017: Estimating spatially distributed turbulent heat fluxes from high-resolution thermal imagery acquired with a UAV system. Int. J. Remote Sens., 38, 3003-3026, https://doi.org/10.1080/01431161.2017.1280202.

Brubaker, K. L., and D. Entekhabi, 1995: An analytic approach to modeling the land-atmosphere interaction: 1 . Construct and equilibrium behavior. Water Resour. Res., 31, 619-632, https:// doi.org/10.1029/94WR01772.

Brutsaert, W., 2005: Hydrology: An Introduction. Cambridge University Press, 618 pp.

Caparrini, F., F. Castelli, and D. Entekhabi, 2003: Mapping of landatmosphere heat fluxes and surface parameters with remote sensing data. Bound.-Layer Meteor., 107, 605-633, https:// doi.org/10.1023/A:1022821718791.

,-- , and,$- 2004 \mathrm{a}$ : Estimation of surface turbulent fluxes through assimilation of radiometric surface temperature sequences. J. Hydrometeor., 5, 145-159, https://doi.org/10.1175/ 1525-7541(2004)005<0145:EOSTFT>2.0.CO;2. 
,-- , and $-2004 \mathrm{~b}$ : Variational estimation of soil and vegetation turbulent transfer and heat flux parameters from sequences of multisensor imagery. Water Resour. Res., 40, W12515, https://doi.org/10.1029/2004WR003358.

Castelli, F., D. Entekhabi, and E. Caporali, 1999: Estimation of surface heat flux and an index of soil moisture using adjointstate surface energy balance. Water Resour. Res., 35, 31153125, https://doi.org/10.1029/1999WR900140.

Chen, F., K. Mitchell, J. Schaake, Y. Xue, H.-L. Pan, V. Koren, Q. Y. Duan, M. Ek, and A. Betts, 1996: Modeling of land surface evaporation by four schemes and comparison with FIFE observations. J. Geophys. Res., 101, 7251-7268, https://doi.org/ 10.1029/95JD02165.

Crow, W. T., and W. P. Kustas, 2005: Utility of assimilating surface radiometric temperature observations for evaporative fraction and heat transfer coefficient retrieval. Bound.-Layer Meteor., 115, 105-130, https://doi.org/10.1007/s10546-004-2121-0.

Daley, R., 1991: Atmospheric Data Analysis. Cambridge University Press, 466 pp.

de Lannoy, G. J. M., P. de Rosnay, and R. H. Reichle, 2016: Soil moisture data assimilation. Handbook of Hydrometeorological Ensemble Forecasting, Q. Duan et al., Eds., Springer, 1-43, https://doi.org/10.1007/978-3-642-40457-3_32-1.

de Rosnay, P., M. Drusch, D. Vasiljevic, G. Balsamo, C. Albergel, and L. Isaksen, 2013: A simplified extended Kalman filter for the global operational soil moisture analysis at ECMWF. Quart. J. Roy. Meteor. Soc., 139, 1199-1213, https://doi.org/ 10.1002/qj.2023.

Douville, H., P. Viterbo, J. F. Mahfouf, and A. C. Beljaars, 2000: Evaluation of the optimum interpolation and nudging techniques for soil moisture analysis using FIFE data. Mon. Wea. Rev., 128, 1733-1756, https://doi.org/10.1175/15200493(2000)128<1733:EOTOIA > 2.0.CO;2.

Drusch, M., and P. Viterbo, 2007: Assimilation of screen-level variables in ECMWF's integrated forecast system: A study on the impact on the forecast quality and analyzed soil moisture. Mon. Wea. Rev., 135, 300-314, https://doi.org/10.1175/ MWR3309.1.

Duynkerke, P. G., 1992: The roughness length for heat and other vegetation parameters for a surface of short grass. J. Appl. Meteor., 31, 579-586, https://doi.org/10.1175/1520-0450(1992) $031<0579$ :TRLFHA $>2.0$. CO; 2 .

Garcia, J. R., and J. P. Mellado, 2014: The two-layer structure of the entrainment zone in the convective boundary layer. J. Atmos. Sci., 71, 1935-1955, https://doi.org/10.1175/JAS-D-13-0148.1.

Garratt, J. R., 1994: The Atmospheric Boundary Layer. Cambridge University Press, $336 \mathrm{pp}$.

Gentine, P., D. Entekhabi, A. Chehbouni, G. Boulet, and B. Duchemin, 2007: Analysis of evaporative fraction diurnal behavior. Agric. For. Meteor., 143, 13-29, https://doi.org/ 10.1016/j.agrformet.2006.11.002.

—, _ , and J. Polcher, 2011: The diurnal behavior of evaporative fraction in the soil-vegetation-atmospheric boundary layer. J. Hydrometeor., 12, 1530-1546, https://doi.org/10.1175/ 2011JHM1261.1.

- G. Bellon, and C. C. van Heerwaarden, 2015: A closer look at boundary layer inversion in large-eddy simulations and bulk models: buoyance-driven case. J. Atmos. Sci., 72, 728-749, https://doi.org/10.1175/JAS-D-13-0377.1.

, A. Chhang, A. Rigden, and G. Salvucci, 2016: Evaporation estimates using weather station data and boundary layer theory. Geophys. Res. Lett., 43, 11 661-11670, https://doi.org/ 10.1002/2016GL070819.
Hall, F. G., K. F. Huemmrich, S. J. Goetz, P. J. Sellers, and J. E. Nickerson, 1992: Satellite remote sensing of surface energy balance: Success, failures, and unresolved issues in FIFE. J. Geophys. Res., 97, 19 061-19 089, https://doi.org/10.1029/ 92JD02189.

Hess, R., 2001: Assimilation of screen-level observations by variational soil moisture analysis. Meteor. Atmos. Phys., 77, 145-154, https://doi.org/10.1007/s007030170023.

Holtslag, A. A. M., and A. P. Van Ulden, 1983: A single scheme for daytime estimates of the surface fluxes from routine weather data. J. Climate Appl. Meteor., 22, 517-529, https://doi.org/ 10.1175/1520-0450(1983)022<0517:ASSFDE $>2.0$.CO;2.

Idso, S. B., 1981: A set of equations for full spectrum and 8- to $14-\mu \mathrm{m}$ and 10.5 - to $12.5-\mu \mathrm{m}$ thermal radiation from cloudless skies. Water Resour. Res., 17, 295-304, https://doi.org/10.1029/ WR017i002p00295.

Jimenez, P. A., J. Dudhia, J. F. Gonzalez-Rouco, J. Navarro, J. P. Montavez, and E. Garcia-Bustamante, 2012: A revised scheme for the WRF surface layer formulation. Mon. Wea. Rev., 140, 898-918, https://doi.org/10.1175/MWR-D-11-00056.1.

Kalma, J. D., T. R. McVicar, and M. F. McCabe, 2008: Estimating land surface evaporation: A review of methods using remotely sensed surface temperature data. Surv. Geophys., 29, 421-469, https://doi.org/10.1007/s10712-008-9037-z.

Kim, C. P., and D. Entekhabi, 1997: Examination of two methods for estimating regional evapotranspiration using a coupled mixed-layer and surface mode. Water Resour. Res., 33, 21092116, https://doi.org/10.1029/97WR01564.

$\longrightarrow$, and $\longrightarrow$, 1998a: Impact of soil heterogeneity in a mixedlayer model of the planetary boundary layer. Hydrol. Sci. J., 43, 633-658, https://doi.org/10.1080/02626669809492158.

$\longrightarrow$, and -1998 b: Feedbacks in the land-surface and mixedlayer energy budgets. Bound.-Layer Meteor., 88, 1-21, https:// doi.org/10.1023/A:1001094008513.

Li, Y., Z. Gao, D. H. Lenschow, and F. Chen, 2010: An improved approach for parameterizing surface-layer turbulent transfer coefficients in numerical models. Bound.-Layer Meteor., 137, 153-165, https://doi.org/10.1007/s10546-010-9523-y.

Liou, Y.-A., and S. K. Kar, 2014: Evapotranspiration estimation with remote sensing and various surface energy balance algorithms-A review. Energies, 7, 2821-2849, https://doi.org/ 10.3390/en7052821.

Lu, Y., J. Dong, S. C. Steele-Dunne, and N. van de Giesen, 2016: Estimating surface turbulent heat fluxes from land surface temperature and soil moisture observations using the particle batch smoother. Water Resour. Res., 52, 9086-9108, https:// doi.org/10.1002/2016WR018943.

Lum, M., S. M. Bateni, J. Shiri, and A. Keshavarzi, 2017: Estimation of reference evapotranspiration from climatic data. Int. J. Hydrol., 1, 25-30, https://doi.org/10.15406/IJH.2017.01.00005.

Maes, W. H., and K. Steppe, 2012: Estimating evapotranspiration and drought stress with ground-based thermal remote sensing in agriculture: A review. J. Exp. Bot., 63, 4671-4712, https:// doi.org/10.1093/jxb/ers165.

Mahfouf, J.-F., 1991: Analysis of soil moisture from nearsurface parameters: A feasibility study. J. Appl. Meteor., 30, 1534-1547, https://doi.org/10.1175/1520-0450(1991) $030<1534$ :AOSMFN $>2.0 . \mathrm{CO} ; 2$.

—, P. Viterbo, H. Douville, A. Beljaars, and S. Saarinen, 2000: A revised land-surface analysis scheme in the Integrated Forecasting System. ECMWF Newsletter, No. 88, ECMWF, Reading, United Kingdom, 8-13, https://www.ecmwf.int/ node/14636. 
—_, K. Bergaoui, C. Draper, F. Bouyssel, F. Taillefer, and L. Taseva, 2009: A comparison of two off-line soil analysis schemes for assimilation of screen level observations. J. Geophys. Res., 114, D08105, https://doi.org/10.1029/ 2008JD011077.

Margulis, S. A., 2002: Variational sensitivity analysis and data assimilation studies of the coupled land surface-atmospheric boundary layer system. Ph.D. thesis, Massachusetts Institute of Technology, 205 pp., https://dspace.mit.edu/handle/1721.1/ 17525 .

_- , and D. Entekhabi, 2001: A coupled land surface-boundary layer model and its adjoint. J. Hydrometeor., 2, 274-296, https://doi.org/10.1175/1525-7541(2001)002<0274:ACLSBL > 2.0.CO;2.

- , and -2003 : Variational assimilation of radiometric surface temperature and reference-level micrometeorology into a model of the atmospheric boundary layer and land surface. Mon. Wea. Rev., 131, 1272-1288, https://doi.org/10.1175/15200493(2003)131<1272:VAORST>2.0.CO;2.

Ren, D., and M. Xue, 2016: Retrieval of land surface model state variables through assimilating screen level humidity and temperature measurements. Adv. Meteor., 2016, 1905076, https:// doi.org/10.1155/2016/1905076

Rigden, A. J., and G. D. Salvucci, 2015: Evapotranspiration based on equilibrated relative humidity (ETRHEQ): Evaluation over the continental U. S. Water Resour. Res., 51, 2951-2973, https://doi.org/10.1002/2014WR016072.

Salvucci, G. D., and P. Gentine, 2013: Emergent relation between surface vapor conductance and relative humidity profiles yields evaporation rates from weather data. Proc. Natl. Acad. Sci. USA, 110, 6287-6291, https://doi.org/ 10.1073/PNAS.1215844110.

Santanello, J. A., and Coauthors, 2018: Land-atmosphere interactions: The LoCo perspective. Bull. Amer. Meteor. Soc., 99, 1253-1272, https://doi.org/10.1175/BAMS-D17-0001.1.

Shang, K. Z., S. G. Wang, Y. X. Ma, Z. J. Zhou, J. Y. Wang, H. L. Liu, and Y. Q. Wang, 2007: A scheme for calculating soil moisture content by using routine weather data. Atmos. Chem. Phys., 7, 5197-5206, https://doi.org/10.5194/acp-7-51972007.

Shuttleworth, W. J., 2012: Terrestrial Hydrometeorology. Wiley, $472 \mathrm{pp}$.

Sini, F., G. Boni, F. Caparrini, and D. Entekhabi, 2008: Estimation of large-scale evaporation fields based on assimilation of remotely sensed land temperature. Water Resour. Res., 44, W06410, https://doi.org/10.1029/2006WR005574.

Smeda, M. S., 1979: A bulk model for the atmospheric planetary boundary layer. Bound.-Layer Meteor., 17, 411-428, https:// doi.org/10.1007/BF00118608.

Strebel, D. E., D. R. Landis, K. F. Huemmrich, and B. W. Meeson, 1994: Collected data of the First ISLSCP Field Experiment, Vol. 1: Surface observations and non-image data sets. NASA GSFC, CD-ROM.

Stull, R. B., 1994: An Introduction to Boundary Layer Meteorology. Kluwer Academic, 670 pp.

Tajfar, E., 2019: Estimation of turbulent heat fluxes via the synergistic assimilation of land surface temperature, air temperature and specific humidity into a variational data assimilation model. Ph.D. thesis, University of Hawai'i at Manoa, 211 pp., http://hdl.handle.net/10125/63483.

Van Heerwaarden, C. C., J. Vilà-Guerau de Arellano, A. Gounou, F. Guichard, and F. Couvreux, 2010: Understanding the daily cycle of evapotranspiration: a method to quantify the influence of forcings and feedbacks. J. Hydrometeor., 11, 1405-1422, https://doi.org/10.1175/2010JHM1272.1.

Xu, T., S. M. Bateni, S. Liang, D. Entekhabi, and K. Mao, 2014: Estimation of surface turbulent heat fluxes via variational assimilation of sequences of land surface temperatures from Geostationary Operational Environmental Satellites. J. Geophys. Res. Atmos., 119, 10 780-10 798, https://doi.org/ 10.1002/2014JD021814.

— — - and — 2015: Estimating turbulent heat fluxes with a weak-constraint data assimilation scheme: A case study (HiWATER-MUSOEXE). IEEE Geosci. Remote Sens. Lett., 12, 68-72, https://doi.org/10.1109/LGRS.2014.2326180.

,,-- S. A. Margulis, L. Song, and S. Lio, 2016: Partitioning evapotranspiration into soil evaporation and canopy transpiration via a two-source variational data assimilation system. J. Hydrometeor., 17, 2353-2370, https://doi.org/10.1175/ JHM-D-15-0178.1.

- — C. M. U. Neale, T. Auligne, and S. Liang, 2018: Estimation of turbulent heat fluxes by assimilation of land surface temperature observations from GOES satellites into an ensemble Kalman smoother framework. J. Geophys. Res. Atmos., 123, 2409-2423, https://doi.org/10.1002/2017JD027732.

Zhuang, Q., and B. Wu, 2015: Estimating evapotranspiration from an improved tow-source energy balance model using ASTER satellite imagery. Water, 7, 6673-6688, https://doi.org/10.3390/ w7126653. 